\title{
Convection Initiation and Growth at the Coast of South China. Part II: Effects of the Terrain, Coastline, and Cold Pools
}

\author{
Yu Du, Guixing Chen, Bin Han, And Lanqiang Bai \\ School of Atmospheric Sciences, Sun Yat-sen University, and Key Laboratory of Tropical Atmosphere-Ocean System, \\ Ministry of Education, and Southern Marine Science and Engineering Guangdong Laboratory (Zhuhai), Zhuhai, China \\ MiNGHUA LI \\ Meteorological Bureau of Shenzhen Municipality, and Key Laboratory of Severe Weather in South China, Shenzhen, China
}

(Manuscript received 20 March 2020, in final form 15 July 2020)

\begin{abstract}
Through conducting dynamic and thermodynamic diagnoses as well as a series of numerical sensitivity simulations, we investigated the effects of the terrain, coastline, and cold pools on convection initiation (CI) and its subsequent upscale convective growth (UCG) during a case of heavy rainfall along the coast of South China. CI occurred at the vertex of the coastal concave mountain geometry as a combined result of coastal convergence, orographic lifting, and mesoscale ascent driven by the terminus of a marine boundary layer jet (MBLJ). In numerical simulations with the coastline or terrain of South China removed, the coastal CI does not occur or becomes weaker as the MBLJ extends farther north, suggesting that the coastline and terrain play a role in CI. In addition, local small-scale terrain can modulate the detailed location and timing of CI and UCG. When the coastal concave terrain and coastline near the CI are artificially removed or filled by additional mountains, the orographic lifting and the local convergence along the coast correspondingly change, which strongly affects the CI and UCG. From a thermodynamic perspective, the coastal concave terrain plays the role of a local moisture "catcher," which promotes low-level moistening by blocking water vapor coming from an upstream moist tongue over the ocean. Furthermore, new convection is continuously generated by the lifting of low-level moist southerlies at the leading edges of cold pools that tend to move southeastward because of the blocking coastal mountains. Sensitivity experiments suggest that the MCS becomes weaker and moves more slowly when cold pools are weakened through a reduction of rain-evaporation cooling.
\end{abstract}

\section{Introduction}

Heavy rainfall is frequently observed near coastal terrain as a result of processes including continuous convection initiation $(\mathrm{CI})$ and upscale convective growth (UCG) (Lin et al. 2001; Ducrocq et al. 2008; Lee et al. 2014; Bai et al. 2020a,b). Three important physical setting components influencing CI and UCG at the coast have been identified: ocean, coastline, and coastal mountains. The ocean typically acts as a main source of moisture and heat by providing sensible and latent heat fluxes (Buzzi et al. 1998). The oceanic moist low-level flow or low-level jet (LLJ) transports the moisture and heat required for persistent coastal rainfall (Phadtare 2018; Du et al. 2020, hereafter Part I). The sea surface temperature (SST) is found to modulate the intensity but not the location of

Corresponding author: Yu Du, duyu7@mail.sysu.edu.cn heavy coastal rainfall (Lebeaupin et al. 2006; Part I). Additionally, the coastline provides a surface discontinuity in roughness and temperature and therefore may induce low-level convergence and enhance rainfall in coastal areas (Bergeron 1949; Lee et al. 2019). Lee et al. (2014) suggested that onshore convection is more profound than offshore convection because of stronger convergence at low levels caused by friction over land.

In addition to the ocean and coastline, the role of terrain in CI and UCG has been widely documented (e.g., Lin et al. 2001; Smith 2019). To improve the understanding of the mechanisms of topographic rainfall, multiple field campaigns have been conducted such as the Mesoscale Alpine Programme (Rotunno and Houze 2007), the Convective and Orographically-induced Precipitation Study (COPS; Wulfmeyer et al. 2011) and the Southwest Monsoon Experiment/TerrainInfluenced Monsoon Rainfall Experiment (Davis and 
Lee 2012). Previous studies found that orographic precipitation is attributed to a complex combination of multiscale dynamic processes (Rotunno and Houze 2007). Lin et al. (2001) summarized the common elements of orographic precipitation, including 1) a conditionally or potentially unstable flow impinging on the mountains, 2) a very moist LLJ, 3) a steep mountain, 4) a quasi-stationary synoptic system, 5) strong synoptic forcing, and 6) a concave mountain geometry. Under such favorable conditions, orographic convection is triggered and subsequently develops with the aid of orographic uplift (Yu et al. 2007; Maddox et al. 1978), lifting over orographically blocked flow (Neiman et al. 2002; Yu and Hsieh 2009), the formation of convergence (Rotunno and Ferretti 2001; Wang et al. 2000) and thermal forcings (Romero et al. 2000; Soderholm et al. 2014).

In general, when intense low-level moist flows or LLJs impinge on mountainous terrain, it results in orographic lifting as well as an adequate supply of moisture near the mountains (Maddox 1983; Buzzi and Foschini 2000; Nuissier et al. 2008; Tu et al. 2019). The behavior of low-level flows blocked by terrain varies for different mountain shapes (height and width) and atmospheric characteristics (stratification and winds), which affect the coastal rainfall intensity and patterns (Smith 1979; Miglietta and Rotunno 2009, 2010, 2012, 2014). Chu and Lin (2000) identified three moist-flow regimes including upstream, quasi-stationary and downstreampropagating convective systems under variations in the flow intensity, stability and terrain shape. Furthermore, moisture-related processes (e.g., latent heating and cold pools) also play an important role in orographic rainfall. For instance, latent heating and evaporative cooling can alter stratification and orographic blocking (Smith and Lin 1982; Miglietta and Buzzi 2001, 2004). Cold pool outflows resulting from the evaporation of precipitation often trigger convection and sustain quasistationary convection at the edge of the cold pool upstream of the mountains where impinging airflow is forcibly lifted (Rotunno et al. 1988; Ducrocq et al. 2008; Liu et al. 2018). Terrain height influences the blocking of cold pools and thereby affects UCG processes (Mulholland et al. 2019). The interactions among strong impinging airflow (e.g., low-level jet), cool pools and the coastal orography were revealed for the extreme rainfall (Phadtare 2018).

In East Asia, coastal and orographic rainfall occurs frequently and causes large economic and human losses. The southwest coast of Taiwan is one of the most studied regions for the orographic influence on rainfall (Chen and Yu 1988; Chen et al. 1991; Li et al. 1997; Davis and Lee 2012; Xu et al. 2012). Under the influence of the
East Asian monsoon (or marine boundary layer jet), the dynamic lifting forced by the lower-tropospheric southwesterly flow over the Central Mountain Range of Taiwan results in heavy rainfall over the southwest coast of Taiwan (upwind of the mountains, Tu et al. 2019). Xu et al. (2012) further stressed the role of topographically trapped cold pools that provide the necessary low-level lifting for secondary CI offshore from the topography for the maintenance of a long-lived, nearly stationary mesoscale convective system (MCS) near the southwest coast of Taiwan. Over the relatively flat terrain of Korea, a sustained heavy rainfall event along the west coast of Korea was caused by a convergence line at the surface induced by the variation in sea-land roughness (Lee et al. 2019).

The diversity of mountains and coastlines across mainland China results in a broad spectrum of rainfall effects. A nocturnal LLJ interacting with complex mountains in eastern China induces mechanical lifting and local convergence on the windward side of the mountains that are favorable for the formation and development of nocturnal MCSs (Zhao 2012; Fu et al. 2019; Du and Chen 2019b). On the southern coast of China, both coastal convergence and topographic lifting are found to influence CI and UCG near the coastal terrain ( $\mathrm{Li}$ et al. 2020; Chen et al. 2017; Luo et al. 2017; Du and Chen 2019a; Wu et al. 2020; Bai et al. 2020b; Luo et al. 2020). Chen et al. (2018) showed that these factors, coastal convergence and topographic lifting, are the main factors that induce the climatological hotspots of heavy rainfall near the coastal mountains. Wang et al. (2014) emphasized the importance of a mesoscale boundary between the cold pool outflows and warm air from the South China Sea and Beibu Gulf, resulting in the formation of training rainbands near the southern coast of China. Evidently, various factors involving the coastline, coastal terrain, cold pools, and MBLJ over the adjacent ocean jointly contribute to the CI and UCG along the coast of South China. However, few studies systematically take all those factors into account, and the relative contributions and interactions of these factors are not well understood. For instance, in the presence of a marine boundary layer jet (MBLJ), what is the relative role of the large-scale terrain of South China and the local coastal mountains in CI and UCG? How do low-level flows (or the MBLJ) interact with the coastline and coastal terrain from dynamic and thermodynamic perspectives? How are UCG processes influenced by cold pools that might be blocked by coastal terrain?

The first part of this two-part study concentrated on clarifying the evolution of the mesoscale MBLJ over the adjacent ocean and its impact on CI and UCG near 
the coast of South China during a case of heavy rainfall. The strengthened MBLJ promotes mesoscale ascent on its northwestern edge and terminus where enhanced convergence zones occur. Located directly downstream of the MBLJ, the coastal CI and UCG are dynamically supported by mesoscale ascent. However, the interaction between the MBLJ and coastal terrain needs further clarification. In the current study (Part II), we will thus further examine local forcings including the effects of the terrain, coastlines, and cold pools in the presence of the MBLJ, using high-resolution numerical simulations and relevant sensitivity experiments.

The organization of this paper is as follows. Section 2 presents an overview of the CI and subsequent UCG case study. In section 3, we explore the effects of the terrain and coastline on the coastal CI and UCG in a series of sensitivity experiments through dynamic and thermodynamic diagnosis. In section 4 , the effect of cold pools on UCG is further examined by reducing the latent cooling rates due to the evaporation of rain. The results are summarized in section 5 .

\section{Case overview}

\section{a. Observation}

Two heavy rainfall events were observed on 2122 June 2018 in South China: one occurred near an $850-\mathrm{hPa}$ low pressure anomaly in southwestern China (inland) and the other one was located over the coast of South China near Lufeng (see Fig. 2 of Part I). The synoptic environment is presented as follows: a deep SW-NE-oriented trough at $500 \mathrm{hPa}$ occurred over northern China while an 850-hPa low pressure anomaly occurred over southwestern China. A west-east-oriented shear line at $925 \mathrm{hPa}$ was located to the east of the low pressure anomaly. Our focus in the present study is on the heavy coastal rainfall near Lufeng above $50 \mathrm{~mm}(6 \mathrm{~h})^{-1}$, which had large economic and societal impacts. The heavy coastal rainfall fell far from the low pressure anomaly and its associated shear line, which is a type of warmsector heavy rainfall due to the absence of obvious synoptic forcing. A strong southwesterly MBLJ peaking at approximately $950 \mathrm{hPa}$ prevailed over the northern South China Sea and impinged on the coastal terrain of South China. In the current study, we further focus on the triggering and development of coastal convection under the influence of coastlines, coastal terrain and cold pools in the presence of the MBLJ.

To illustrate the coastal convective processes in detail, the evolution of the observed radar mosaic reflectivity obtained from operational weather radars is shown in Figs. 1a-d. In South China, the majority of radars are S-band radars with a maximum radar range of $460 \mathrm{~km}$ and without any gap in coverage (Bai et al. 2020a). The radar mosaic reflectivity is calculated from an optimal selection from the lowest three elevation angles (i.e., $0.5^{\circ}$, $1.5^{\circ}$, and $2.4^{\circ}$ ), which is called a "terrain-based hybrid scan" (Fulton et al. 1998). CI, defined as the first appearance of radar reflectivity $\geq 35 \mathrm{dBZ}$ (Weckwerth and Parsons 2006), occurred over the foothills of the Lianhua and Nanyang Mountains near Lufeng at approximately 1700-1800 UTC $($ UTC $=$ local time -8 h; Figs. 1a and 1b). The southern portion of Lianhua Mountains and the whole Nanyang Mountains constitute a concave mountain geometry, and CI was located at the vertex of the concave terrain. After the nocturnal CI, convection underwent a UCG process, which is the transition from isolated convection to a larger organized MCS, within the concave region (Figs. 1c,d). The MCS continuously grew as it propagated southeastward and stayed along the coast (Figs. 1c,d). At 2200 UTC, an SW-NE-oriented quasilinear MCS was formed and was characterized by a length of $\sim 350 \mathrm{~km}$ and a width of $\sim 100 \mathrm{~km}$ (Fig. 1d).

\section{b. Numerical simulations}

Convection-permitting simulations using the Weather Research and Forecasting Model (WRF-ARW; Skamarock et al. 2008) are conducted to explore the mechanisms of the CI and UCG in this case (from 1200 UTC 21 June to 1200 UTC 22 June), especially concerning the effects of the terrain, coastline, and cold pools. The model configurations of the control run (CTL run) herein are the same as those in Part I. One-way nested domains with 12- and 4-km horizontal grid spacings and 51 vertical levels are used. Initial and lateral boundary conditions are obtained from NCEP FNL data. For more details on the model setup, please refer to Part I.

The comparison of the convection evolution between the observations and model results is shown in Fig. 1. Similar to the observations, the simulated CI occurs at the vertex of the concave terrain composed of the Lianhua and Nanyang Mountains near Lufeng despite an $\sim 3 \mathrm{~h}$ delay (Figs. 1e,a). The UCG process is generally captured by the simulation as well (Figs. 1e-h). The errors from initial model conditions and physics schemes may greatly influence the simulated CI timing and location. Because of the model spinup issue, the simulated convection tends to be initiated and developed later than the observed convection, as it takes time to generate hydrometeors in the model and achieve downscaling due to the much finer model resolutions than those of the initial conditions (i.e., reanalysis data). But some previous studies (Chen et al. 2002; Lin et al. 2008a,b, 2011; Miao and Yang 2020) found that the simulated convection associated with land-sea breeze tend to occur earlier than the observed convection 


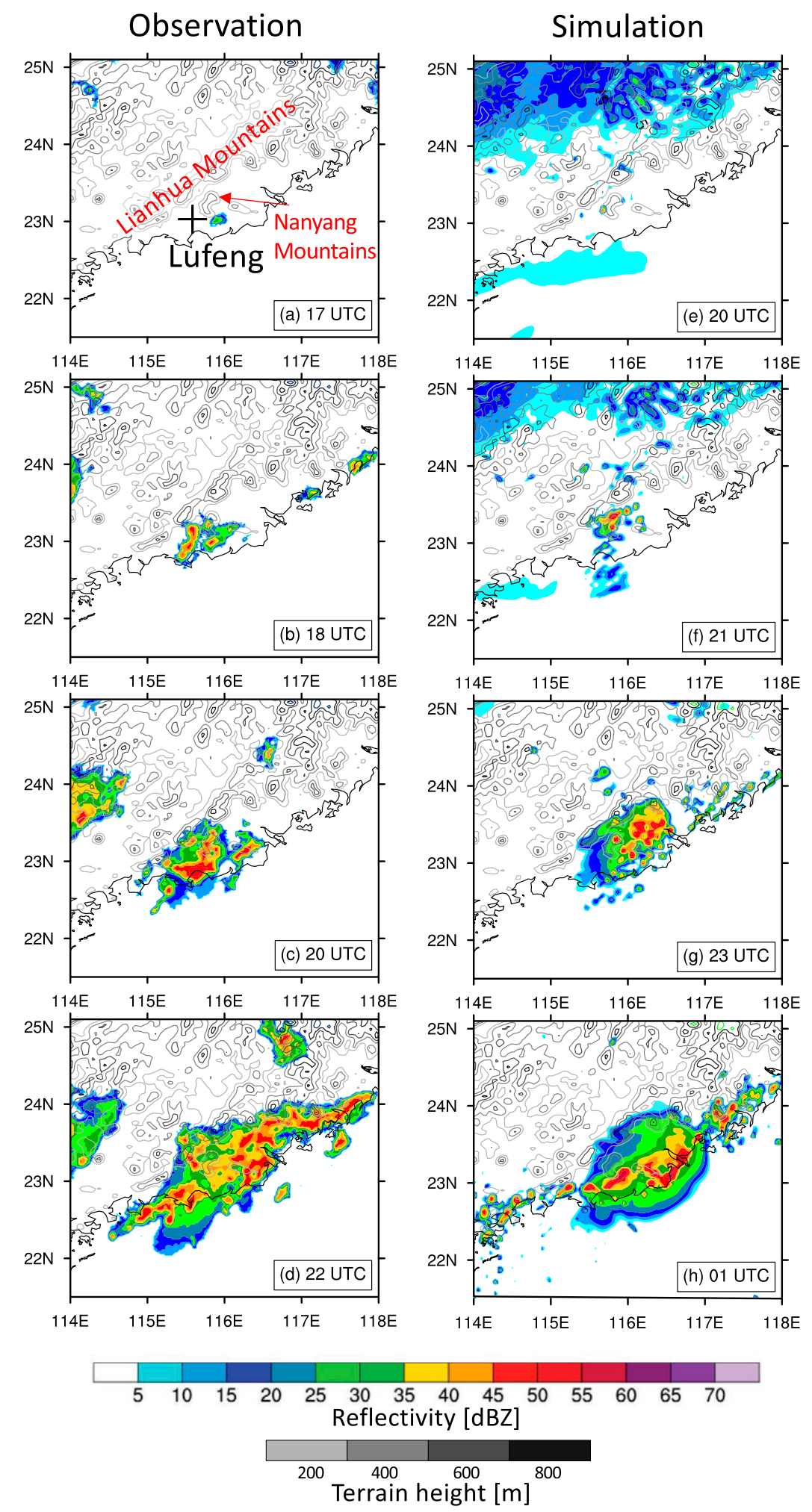

FIG. 1. (a)-(d) Observed radar composite reflectivity (shaded) and terrain contours (intervals of $200 \mathrm{~m}$ ) from 1700 to 2200 UTC 21 Jun 2018. (e)-(h) As (a)-(d), but for simulated radar composite reflectivity from 2000 UTC 21 Jun to 0100 UTC 22 Jun 2018. 
TABLE 1 . The design of the control simulation and the sensitivity experiments.

\begin{tabular}{|c|c|c|}
\hline Expt name & Model configuration & Aim of the experiment \\
\hline CTL & Real model terrain and full physics & To reproduce the CI and UCG processes \\
\hline NOTER_LO & $\begin{array}{l}\text { The large-scale terrain in the white box of Fig. } 2 \mathrm{a} \text { is removed } \\
\text { and replaced by ocean (Fig. 2c) }\end{array}$ & $\begin{array}{l}\text { To explore the impacts of terrain and coastline of } \\
\text { South China }\end{array}$ \\
\hline NOTER_L & $\begin{array}{l}\text { The large-scale terrain in the white box of Fig. } 2 \mathrm{a} \text { is removed } \\
\text { but not replaced by ocean (Fig. } 2 \mathrm{~d} \text { ) }\end{array}$ & To explore the impacts of terrain of South China \\
\hline NOTER_S & $\begin{array}{l}\text { The local concave terrain including the Linahua and Nanyang } \\
\text { Mountains is removed (Fig. 2e) }\end{array}$ & To explore the impacts of local concave terrain \\
\hline NOTER_SO & $\begin{array}{l}\text { The local concave terrain including the Linahua and Nanyang } \\
\text { Mountains is removed and replaced by ocean (Fig. 2f) }\end{array}$ & $\begin{array}{l}\text { To explore the impacts of local concave terrain and } \\
\text { local coastline }\end{array}$ \\
\hline ADDTER_S & $\begin{array}{l}\text { Additional small mountains are added within the concave } \\
\text { region (Fig. } 2 \mathrm{~g} \text { ) }\end{array}$ & To explore the impacts of local concave region \\
\hline EVP_50 & The cooling rate from the rain evaporation is reduced to $50 \%$ & To explore the impact of cold pools \\
\hline EVP_10 & The cooling rate from the rain evaporation is reduced to $10 \%$ & To explore the impact of cold pools \\
\hline
\end{tabular}

possibly due to the urban heat island effect. The time difference in CI between simulation and observation is an interesting issue and needs further investigation. The convection develops and propagates southeastward and finally organizes into a SW-NE-oriented quasi-linear MCS along the coast with an intensity, length, and width similar to those of the observations. Note that the simulated high radar reflectivity of the quasi-linear MCS is mainly confined to the coast, while the observed reflectivity appears both at the coast and onshore on the windward side of the Lianhua Mountains. Despite the timing difference, the similarities in the structure and evolution of the simulation to the observations make it reasonable to use the numerical simulation to analyze the CI and UCG in this case.

\section{The effects of the coastline and terrain}

To clarify the impacts of the coastline and topography on the CI and UCG, a series of sensitivity experiments with respect to terrain are designed and performed in the present study (Table 1 and Fig. 2). Compared to the CTL run, the terrain in the large white box of Fig. 2a is removed $^{1}$ and replaced by the ocean ${ }^{2}$ in the NOTER_LO run [the acronym means no large-scale (L) terrain (TER) with ocean (O), Fig. 2c]. Similar to the NOTER_LO run, the NOTER_L run removes the terrain in the same region but retains the same land properties as those in the CTL run (not replaced by the ocean, Fig. 2d). The NOTER_LO and NOTER_L runs are used to examine

\footnotetext{
${ }^{1}$ Buffer regions are set on the four boundaries of the box with a width of $90 \mathrm{~km}$ where the terrain decreases linearly.

${ }^{2}$ The SST values over the artificial ocean are obtained by horizontal linear extrapolation from the SST values over surrounding ocean points.
}

the impacts of the large-scale topography and coastline of South China. Herein, it is hypothesized that the location and intensity of the MBLJ is sensitive to the presence of coastlines and topography. To study the effect of local terrain close to the CI and UCG, we further modify the local small-scale concave terrain, including the Lianhua and Nanyang Mountains (Fig. 2b), in the NOTER_S [the acronym means no small-scale (S) terrain (TER), Fig. 2e], NOTER_SO (Fig. 2f), and ADDTER_S (Fig. 2g) runs where the MBLJ expectedly varies little. The Lianhua and Nanyang Mountains are removed to eliminate the concave terrain geometry in the NOTER_S run (cf. Figs. 2b and $2 \mathrm{e}$ ), while the concave mountains are not only removed but also replaced by ocean (Fig. 2d). Additional small mountains (similar to the Nanyang Mountains in size and height) are filled within the concave region (inland on the windward side of the Lianhua and Nanyang Mountains) in the ADDTER_S run, as shown in Fig. 2g.

Figure 3 presents the evolutions of the simulated composite reflectivity for the CI and UCG processes in the CTL run as well as the aforementioned sensitivity experiments. The temporal evolution of high-rate precipitation $\left(>20 \mathrm{~mm} \mathrm{~h}^{-1}\right)$ areas over the coastal region (blue box of Fig. 3a) is further shown in Fig. 4. In the NOTER_LO run, CI and UCG do not occur at the location of the coast in the absence of both the terrain and the coastline (Figs. 3e-h, red line of Fig. 4). However, in the NOTER_L run with the existence of the coastline, CI and UCG are delayed by approximately $3-4 \mathrm{~h}$ and occur at the coast instead of inland (Figs. 3i-1) compared to the results of the CTL run (Figs. 3a,b). The range of developed coastal MCS during the UCG process in the NOTER_L run is one-third of that in the CTL run (gray line versus black line of Fig. 4). In contrast to the impact of the large-scale terrain, changing the local concave mountains is anticipated to lead to CI and UCG being more similar to the CTL run but varying in their intensity 


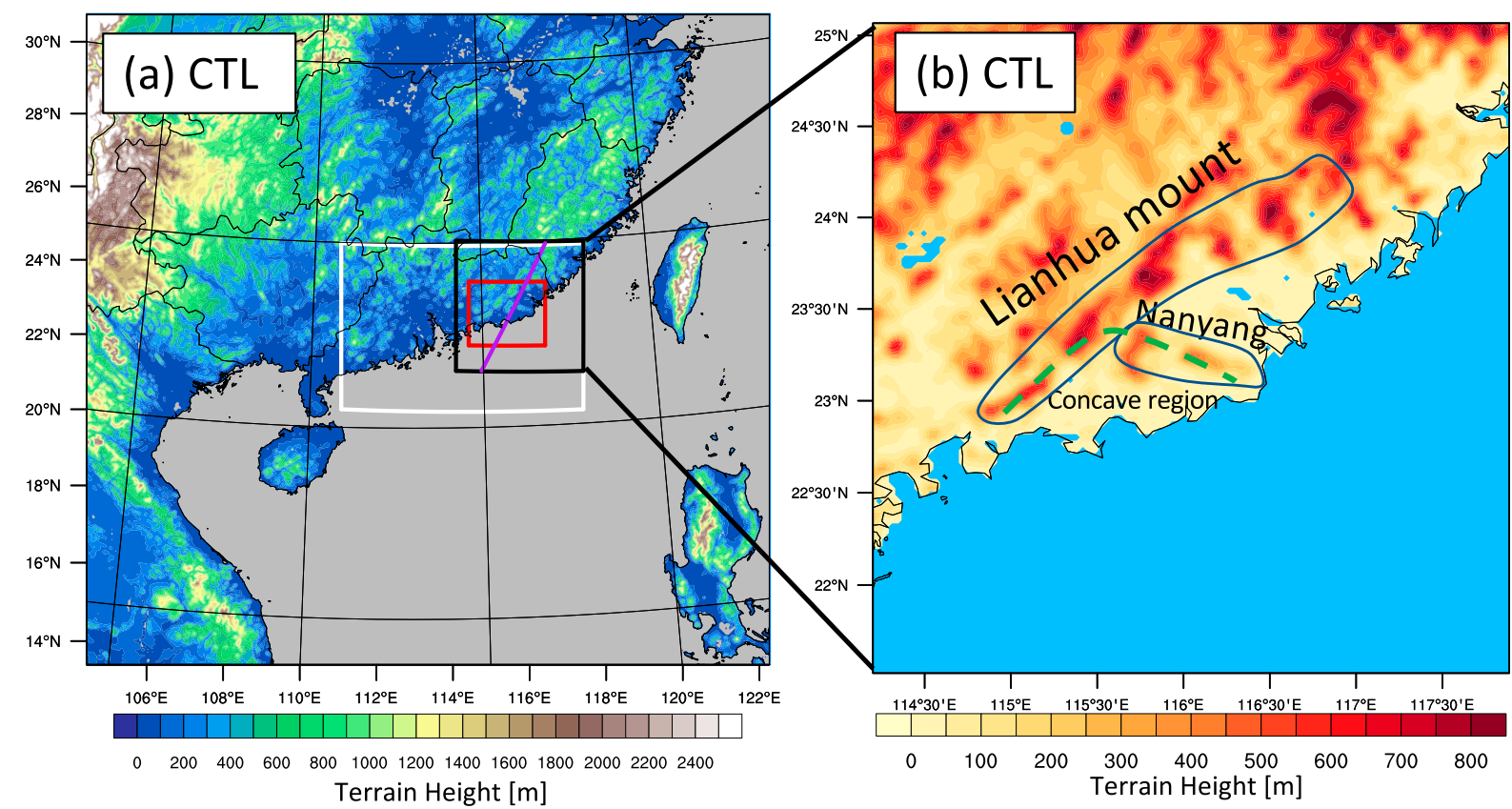

(c) NOTER_LO

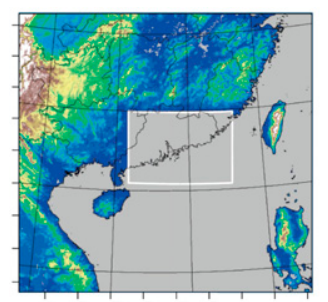

(d) NOTER_L

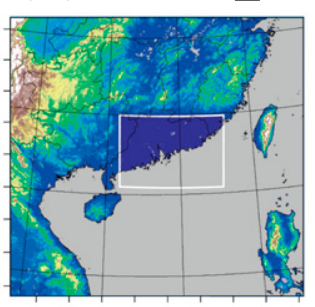

(e) NOTER_S

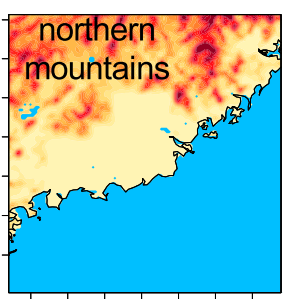

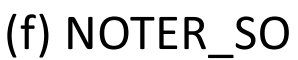

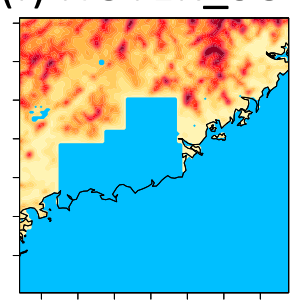

(g) ADDTER_S

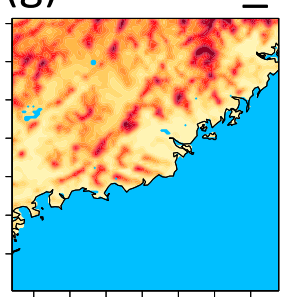

FIG. 2. (a) Terrain height (shaded) in domain 2. The white box is used in the NOTER_LO and NOTER_L runs. The red box is used in Figs. 5 and 6. The purple line is used in Fig. 7. (b) The Lianhua Mountain region is represented by a black box in (a). Experiments (c) NOTER_LO and (d) NOTER_L use the white-box domain and show the terrain height from (a), as modified by the experiments. Experiments (e) NOTER_S, (f) NOTER_SO, and (g) ADDTER_S use the domain and show the terrain heights from (b), as modified by the experiments. In (a), (c), and (d), gray indicates ocean. In (b), (e), (f), and (g), light blue indicates ocean.

and location (Figs. 3m-x), as the MBLJ remains largely the same. In the NOTER_S run where the local concave terrain is removed, convection is generated at the coast rather than at the actual vertex of the concave terrain at 2300 UTC (weaker and delayed by $\sim 2 \mathrm{~h}$ ) and subsequently is organized into a smaller nonlinear MCS ( $\sim 60 \%$ of the size of the control MCS) at the coast (Figs. 3m-p, yellow line of Fig. 4) instead of a linear MCS. With the replacement of the removed concavity with the ocean in the NOTER_SO run, CI appears not only at the location of the coast but also along the foothills of the mountains farther to the north (new coastal mountains). These convective cells then develop individually and merge together afterward (Figs. 3s,t). In the NOTER_SO run, the high precipitation area over the original coast is much smaller $(\sim 2 / 3)$ than that in the CTL run (blue line versus black line of Fig. 4). Compared to the CTL run, convection is triggered $\sim 1 \mathrm{~h}$ earlier in the ADDTER_S run, and gradually develops in the filled concave region nearly without moving (Figs. $3 \mathrm{u}-\mathrm{x}$ ). However, its UCG is slightly weaker than that in the CTL run (green vs black lines of Fig. 4). Therefore, the sensitivity experiments indicate that the terrain and coastline can determine or modulate the CI and UCG processes with regard to their occurrence, intensity, and location. Next, we will examine the dynamic and thermodynamic environments under different topographic scenarios to elucidate the role of the terrain and coastline in CI and UCG.

\section{a. Dynamic effects}

Figures 5 and 6 display the low-level vertical motions ${ }^{3}$ and convergence near the surface at 2000 UTC prior to

\footnotetext{
${ }^{3}$ The height herein is selected to capture the core of the Maritime LLJ near the coast.
} 


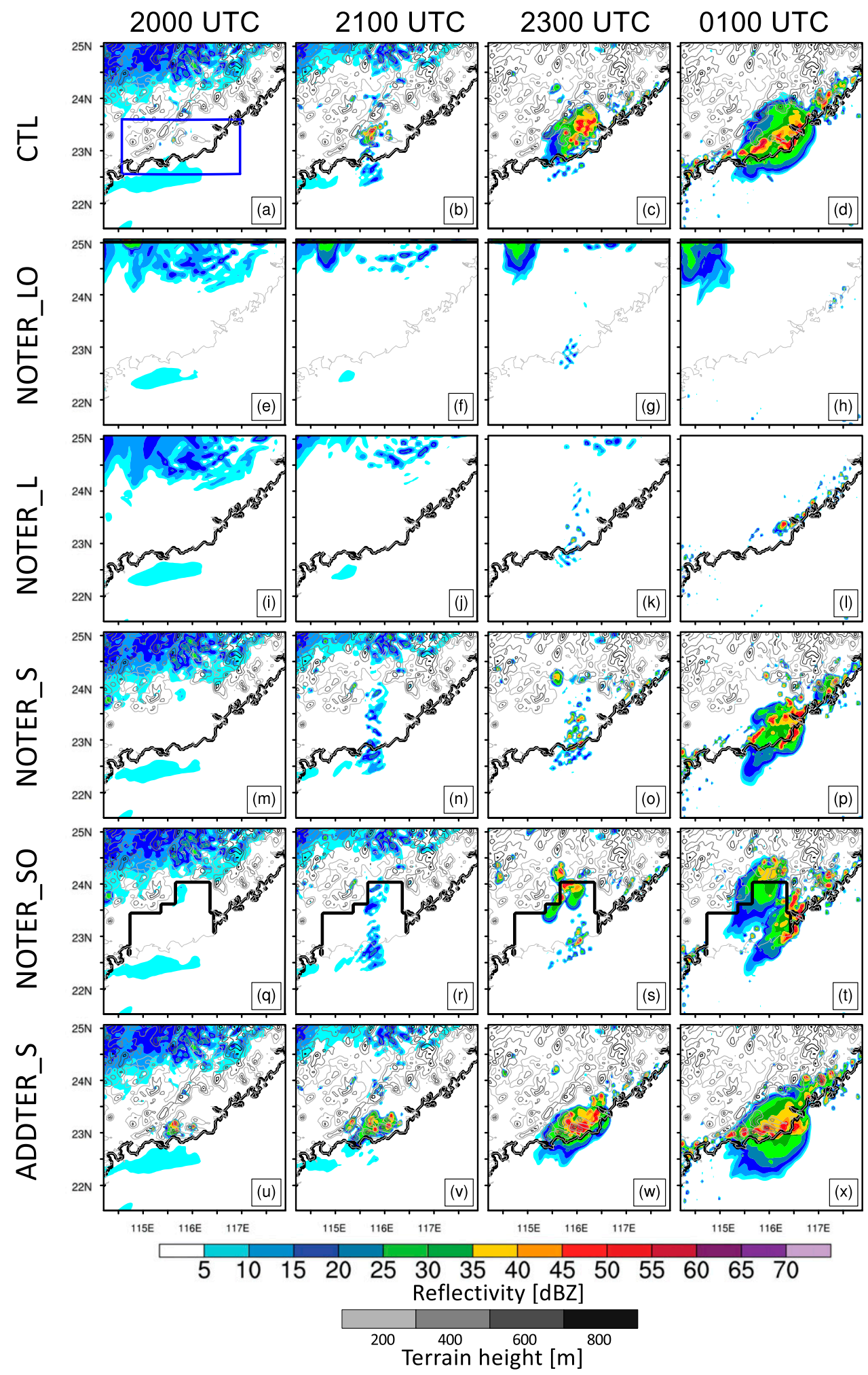

FIG. 3. Radar composite reflectivity with terrain contours (intervals of $200 \mathrm{~m}$ ) in the (a)-(d) CTL, (e)-(h) NOTER_LO, (i)-(l) NOTER_L, (m)-(p) NOTER_S, (q)-(t) NOTER_SO, and (u)-(x) ADDTER_S runs from 2000 UTC 21 Jun to 0100 UTC 22 Jun 2018. The domains are as in Fig. 2b. The thick black lines indicate the coastline. The blue box in (a) is used in Fig. 4. 


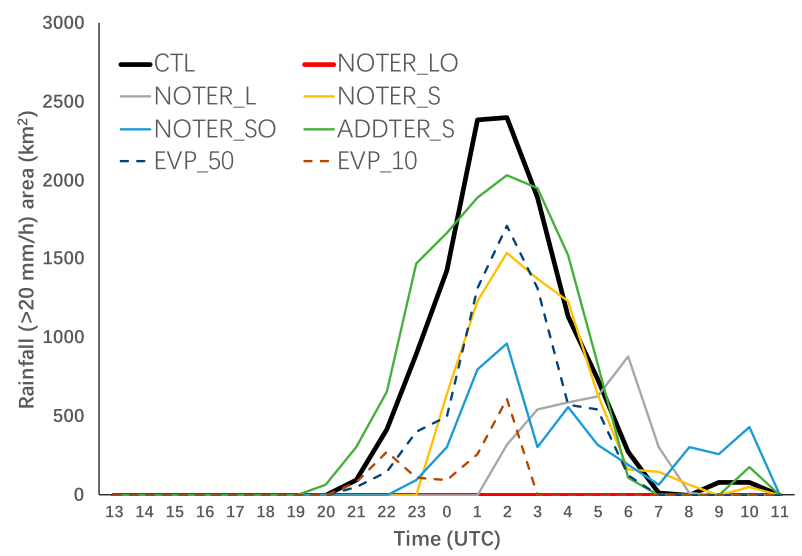

FIG. 4. The evolutions of high-rate precipitation $\left(>20 \mathrm{~mm} \mathrm{~h}^{-1}\right)$ areas $\left(\mathrm{km}^{2}\right)$ over the coastal region (blue box in Fig. 3a) in the CTL, NOTER_LO, NOTER_L, NOTER_S, NOTER_SO, ADDTER_S, EVP_50, and EVP_10 runs.

$\mathrm{CI}$ in the multiple sensitivity experiments. In the CTL run, strong low-level upward motions occur along the coast as well as on the windward sides of the concave mountains, while downward motions concurrently appear on the leeside (Fig. 5a). The reason is because the southwesterly low-level flow of the MBLJ from the ocean impinging on the coastal terrain induces upstream mechanical lifting and downstream subsidence. The convergence near the surface is significant along the coast due to the weakening of onshore low-level flows (Figs. 6a and 7a) with a change in surface roughness between the sea and land (not shown). Hence, the pattern and intensity of low-level vertical motion and convergence associated with the CI and UCG processes are potentially attributed to the terrain and coastline geometry, which will be investigated in the sensitivity experiments.

In the NOTER_LO run in which CI and UCG disappear (Figs. 3e-h), both the low-level upward motion and the convergence become quite weak due to the absence of the mountains and coastline (Figs. 5b and 6b). A similar situation occurs in the NOTER_L run (Fig. 5c), but its convergence near the surface is distinct along the coast (green contours of Fig. 6c) when the coastline exists. Convection is initiated and develops along the coast in the NOTER_L run, but it is much weaker and delayed (Figs. 3i-l) compared to that in the CTL run. The weak and delayed convection might be attributed to weak coastal convergence. In the NOTER_S run, the relatively strong upward motion occurs farther north rather than along the location of the coastal mountains (Fig. 5d), whereas the strong convergence at low levels (at the surface) occurs at the foothills of the northern mountains (near the coastline) (Fig. 6d). The strengths of the upward motion $\left(0.01 \mathrm{~m} \mathrm{~s}^{-1}\right)$ and surface convergence $\left(10 \times 10^{-5} \mathrm{~s}^{-1}\right)$ are not as strong as those in the CTL run $\left(0.03 \mathrm{~m} \mathrm{~s}^{-1}\right.$, $\left.30 \times 10^{-5} \mathrm{~s}^{-1}\right)$. In contrast to the NOTER_S run, in the NOTER_SO run, both the low-level upward motion and the convergence are strengthened together along a new coastline in close proximity to the northern mountains (Figs. 5e and 6e) instead of the location of the actual coastal mountains. In this experiment, $\mathrm{CI}$ is induced farther to the north (over the foothills of the northern mountains) compared to that in the NOTER_S run (cf. Figs. 3s and $3 b$ ). When the concave region is filled by additional mountains (ADDTER_S), the upward motion driven by the additional coastal mountains and coastal convergence are collectively maximized on the windward slope of these additional mountains along the coast and are stronger than those in the CTL run (Figs. 5f and 6f), favoring the earlier $\mathrm{CI}$ occurring even farther to the south.

To illustrate the vertical structures of upstream flows interacting with the coastline and terrain, vertical cross sections of winds along the purple line of Fig. 2a under various terrain scenarios are shown in Fig. 7. In the CTL run, a strong MBLJ peaking at $950-975 \mathrm{hPa}$ impinges on the coastal terrain, which induces mesoscale ascent (indicated by a red ellipse in Fig. 7a) at the terminus of the MBLJ as well as mechanical terrain-induced lifting near the coast (indicated by a white ellipse in Fig. 7a). When the large-scale terrain is removed in the NOTER LO and the NOTER_L runs, the MBLJ migrates more to the north, resulting in weak MBLJ-driven ascent ${ }^{4}$ and no topographic lifting near the location of the actual coast (Figs. 7b,c). In the NOTER_S and NOTER_SO runs (Figs. 7d,e), the relatively strong low-level flows go onshore without the obstacle of the coastal concave terrain, but the general structure and location of the MBLJ remain as in the CTL run. As a result, the mesoscale ascent at the terminus of the MBLJ remains (indicated by a red ellipse in Figs. 7d,e), whereas topographic lifting is evident on the windward slope of the northern mountains (indicated by a white ellipse in Figs. 7d,e) rather than the coastal concave mountains. In the ADDTER_S run, significant low-level lifting at the coast is caused by the combination of MBLJ-driven ascent and topographic lifting (Fig. 7f). Note that the extremely strong upward motions near the coastal terrain might be mainly attributed to convection itself (Fig. 7f) since convection is already initiated at 2000 UTC in the ADDTER_S run (Fig. 3u).

Previous studies have focused on either the terrain effect (e.g., Li et al. 2020) or the impact of the coastline (e.g., Lee et al. 2019), but few studies

\footnotetext{
${ }^{4}$ In the NOTER_LO run, the effect of the coastline cannot be eliminated totally because of spinup issue in the model. Therefore, the deceleration of the MBLJ and vertical ascent remain in part at the original coast.
} 

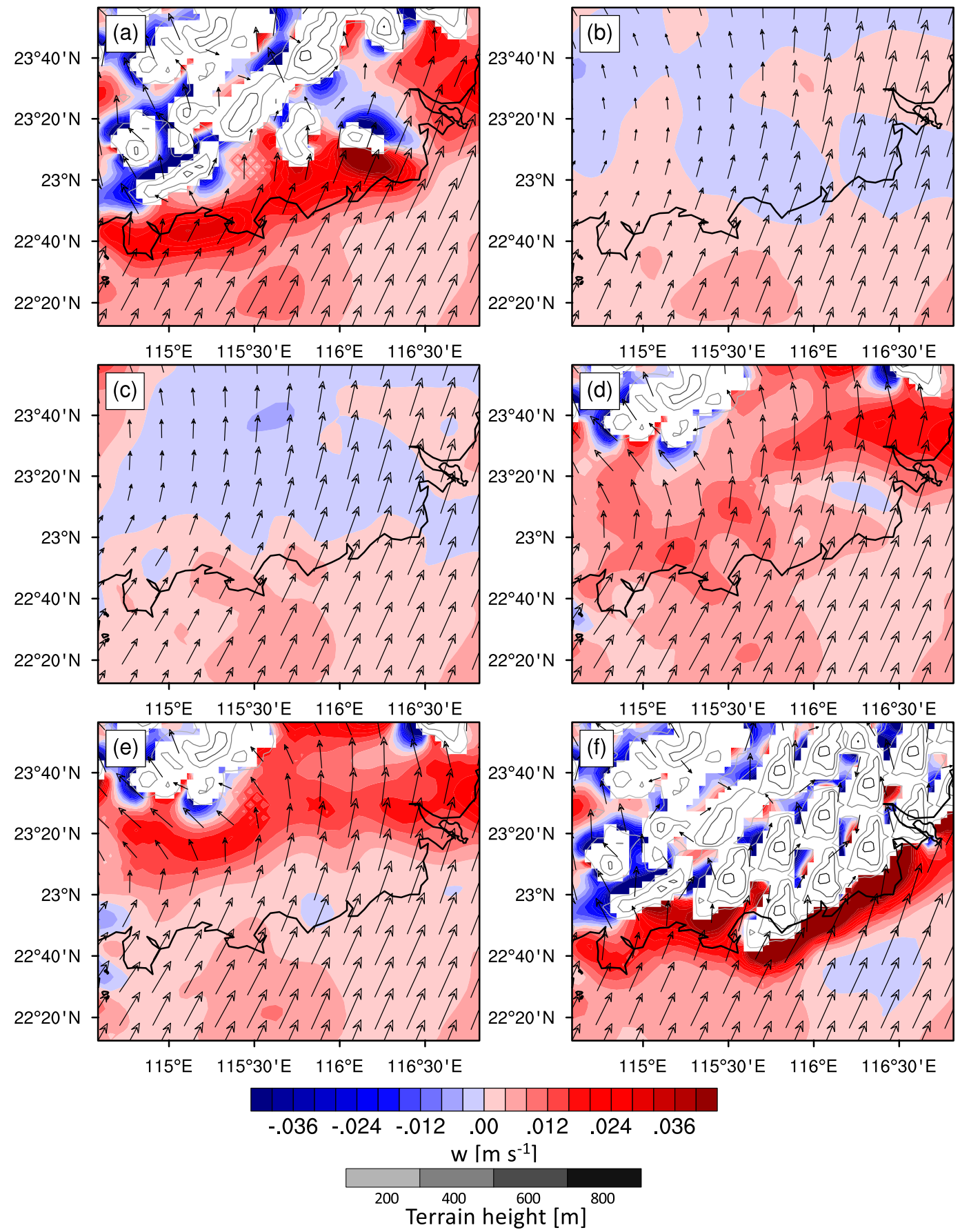

FIG. 5. Vertical velocity at $975 \mathrm{hPa}$ with terrain contours (intervals of $200 \mathrm{~m}$ ) in the red box in Fig. 2a for the (a) CTL, (b) NOTER_LO, (c) NOTER_L, (d) NOTER_S, (e) NOTER_SO, and (f) ADDTER_S runs at 2000 UTC 21 Jun 2018.

consider their relative roles as well as the scale-aware impact (terrain at different scales). Our results show that coastal convergence and topographic lifting jointly affect the coastal CI and UCG. Large-scale terrain can greatly influence the occurrence and intensity of convection as the synoptic background (e.g., MBLJ) alters correspondingly, whereas local small-scale terrain can modulate the specific location and time of CI and UCG.

Thus far, the dynamic impacts of various-scale terrain and coastlines interacting with low-level flows associated with an MBLJ can greatly explain varying CI and UCG processes in the different terrain scenarios. Next, we 

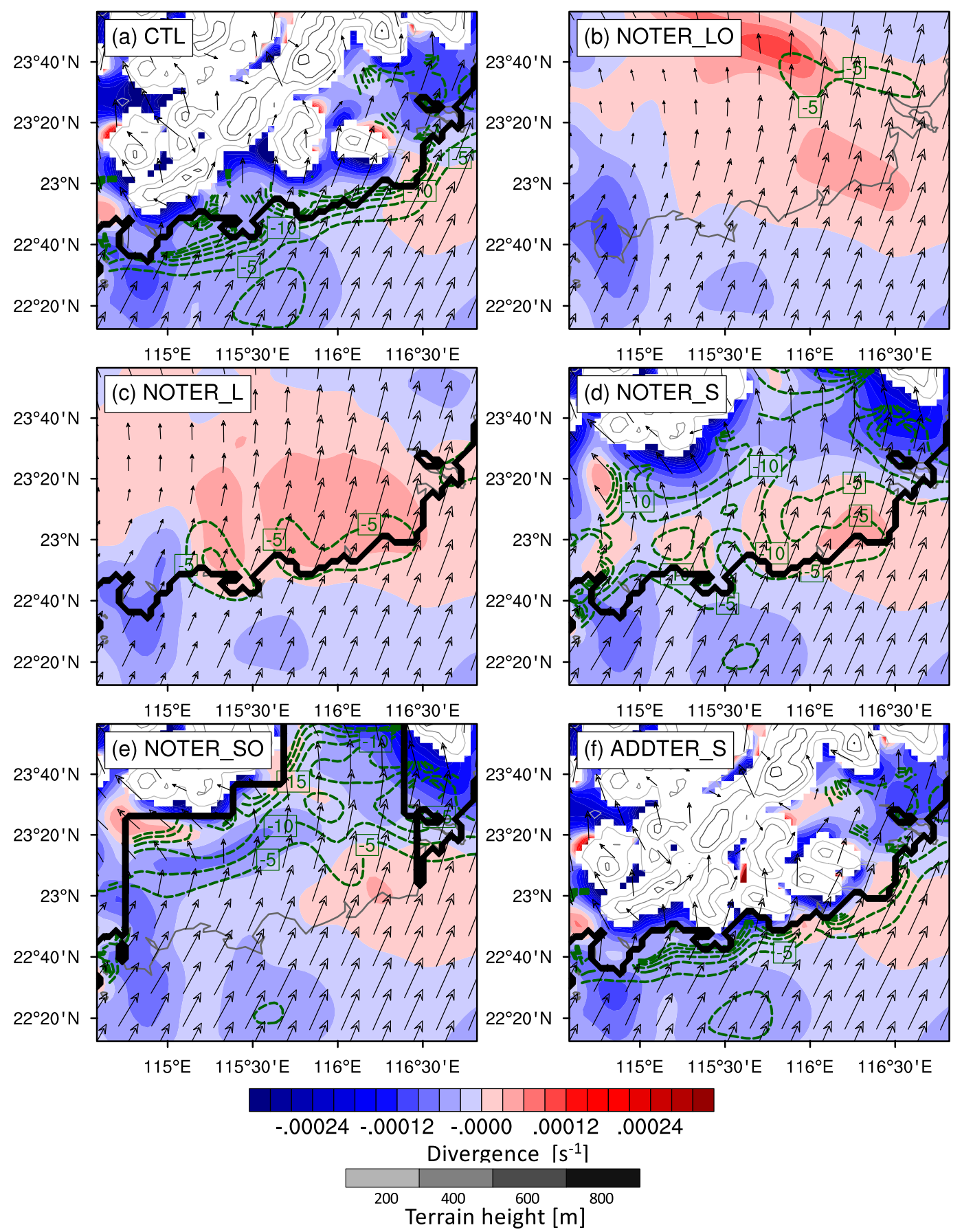

FIG. 6. Divergence at $975 \mathrm{hPa}$ (shaded) and $1000 \mathrm{hPa}$ (green dashed contours, $\leq-5 \times 10^{-5} \mathrm{~s}^{-1}$ ) with terrain black/gray contours (intervals of $200 \mathrm{~m}$ ) in the red box in Fig. 2a for the (a) control run, (b) NOTER_LO, (c) NOTER_L, (d) NOTER_S, (e) NOTER_SO, and (f) ADDTER_S runs at 2000 UTC 21 Jun 2018.

will further examine the role of the terrain and coastline in supporting CI and UCG by its effect on thermodynamics.

\section{b. Thermodynamic effects}

In Part I of this study, we documented that a warm moist air mass tongue over the ocean associated with the MBLJ extends northeastward and arrives at the coastal area. Herein we further study how the warmmoist air mass tongue interacting with the coastal terrain influences the coastal CI and UCG. Since the SW-NE-oriented Lianhua Mountains, the NW-SEoriented Nanyang Mountains, and the coastline jointly 

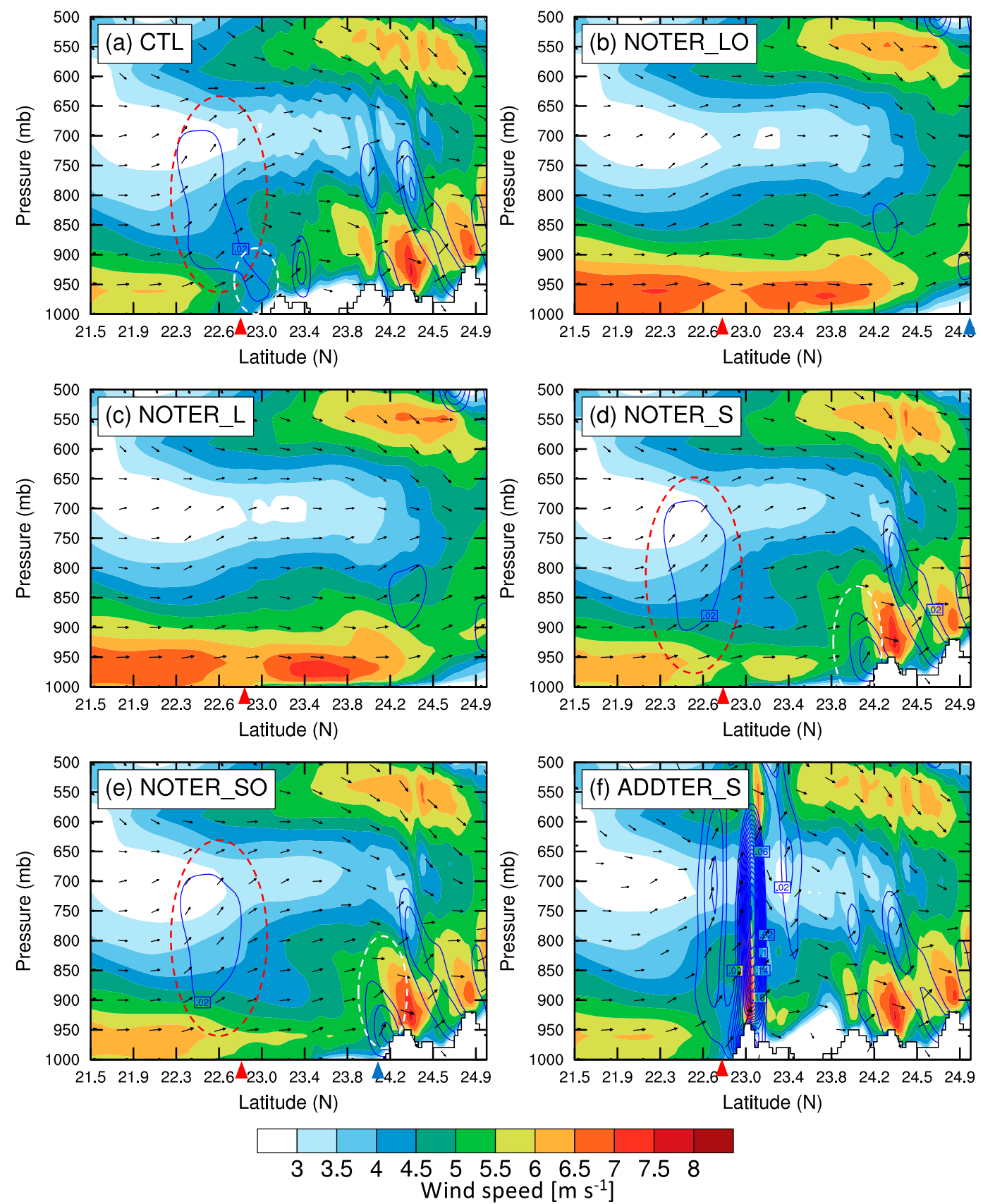

FIG. 7. Vertical cross section of wind speed (shaded), vertical motion (contours, $\geq 0.02 \mathrm{~m} \mathrm{~s}^{-1}$ with an interval of $0.02 \mathrm{~m} \mathrm{~s}^{-1}$ ), and flow vectors (black vectors, wind along the line direction and vertical velocity exaggerated by 100 times) along the purple line in Fig. 2a in the (a) CTL, (b) NOTER_LO, (c) NOTER_L, (d) NOTER_S, (e) NOTER_LO, and (f) ADDTER_S runs at 2000 UTC 21 Jun 2018. The red and blue triangles indicate the locations of the original and new coastlines, respectively.

form a concave region (Fig. 2b), the unique concave region plays the role of a moisture "catcher" that collects and blocks moisture coming from the warm-moist air mass tongue. As a result, the moisture maximum at $950 \mathrm{hPa}$ occurs within the concave region in excess of $20 \mathrm{~g} \mathrm{~kg}^{-1}$ (Fig. 8a).
In the NOTER_LO and NOTER_L runs, the terminus of the warm moist air mass tongue reaches the coastal area, but the water vapor mixing ratio at $950 \mathrm{hPa}$ within the original concave region is relatively small $\left(\sim 18-19 \mathrm{~g} \mathrm{~kg}^{-1}\right)$, and the moisture center is located offshore in the absence of the concave 

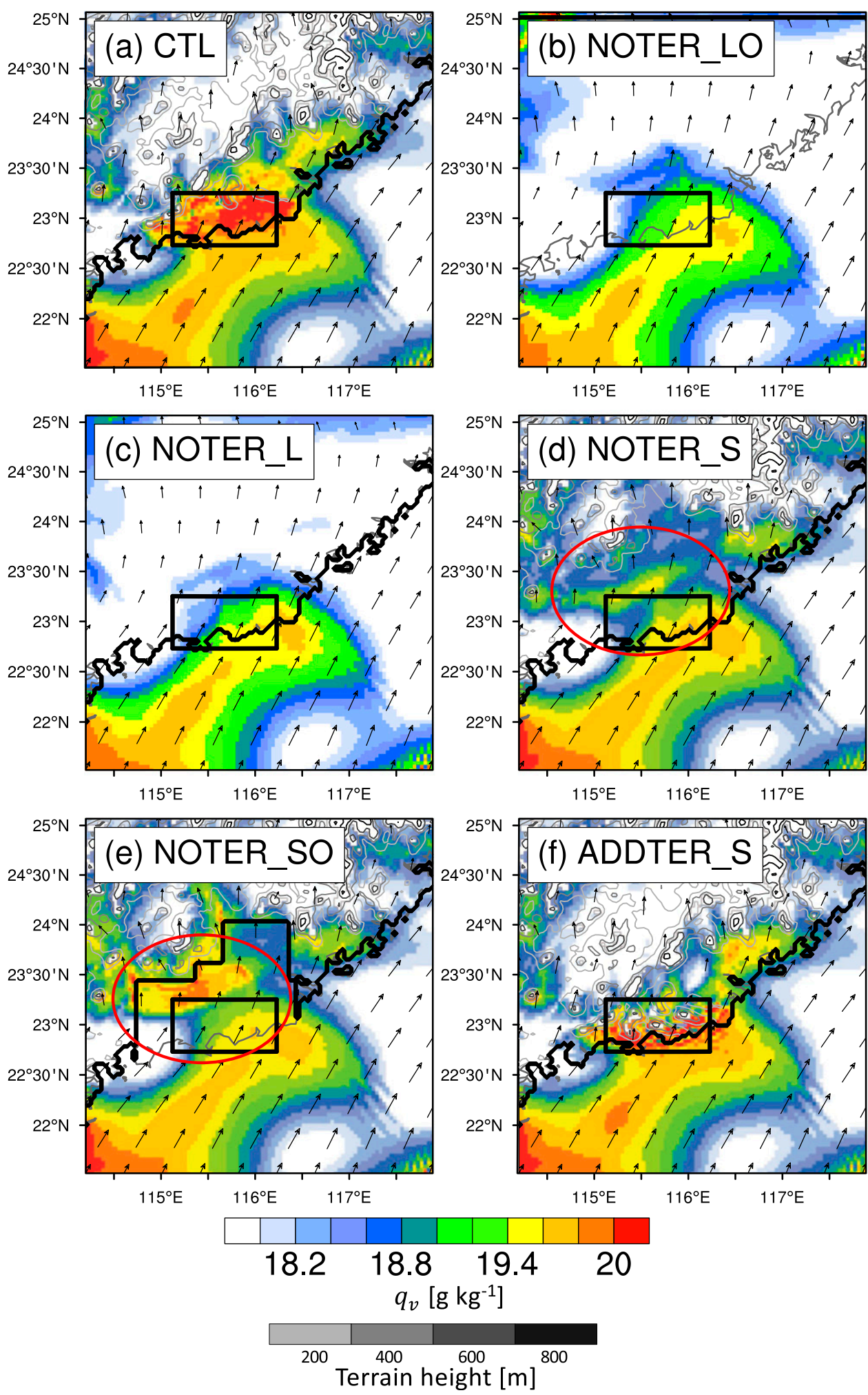

FIG. 8. Distribution of the water vapor mixing ratio (shaded) superimposed with horizontal wind vectors at $950 \mathrm{hPa}$ at 2000 UTC 21 Jun 2018 in the (a) CTL, (b) NOTER_LO, (c) NOTER_L, (d) NOTER_S, (e) NOTER_SO, and (f) ADDTER_S runs. The black/gray terrain contour interval is $200 \mathrm{~m}$. The black box is used in Figs. 9 and 10. The red ellipses indicate the broader region where the moisture spreads north. 
terrain (Figs. 8b,c). When the local concave terrain is removed (Figs. 8d,e), the moisture can be blocked by the northern mountains. The moisture spreads and remains within a broader region with a small peak on the windward side of the northern mountains (indicated by the red ellipses in Figs. 8d,e). The moisture within the broader region in the NOTER_SO run is stronger than that in the NOTER_S run, especially over the foothills of the northern mountains (cf. Figs. $8 \mathrm{~d}$ and $8 \mathrm{e}$ ). This might be because more moisture is transported farther north without coastline convergence, which will be discussed in the subsequent moisture budget. With additional moisture convergence CI and UCG are more likely to occur over the foothills of the northern mountains in the NOTER_SO run than in the NOTER_S run. Additionally, for the ADDTER_S run (Fig. 8f), the moisture is confined in a narrower region along the coast (south portion of the black box in Fig. 8f) resulting from the blocking of additional mountains in the concave region, and therefore has a stronger peak than that in the CTL run.

To further quantify and diagnose the low-level moistening processes within the concave region, the moisture budget at a single level and net vertically integrated low-level moisture fluxes are investigated. In the CTL run, the water vapor mixing ratio $\left(q_{v}\right)$ at $950 \mathrm{hPa}$ averaged over the concave region increases from 17.7 to $19.8 \mathrm{~g} \mathrm{~kg}^{-1}$ during the period $1300-2000$ UTC 21 June 2018 (Fig. 9a). Except for the ADDTER_S run, the increases in $q_{v}$ in other experiments on terrain are smaller than those in the CTL run (Fig. 9a). The results in Part I suggest that the moistening at $950 \mathrm{hPa}$ is mainly attributed to the vertical transport from lower levels containing higher moisture when the local tendency of $q_{v}\left(\partial q_{v} / \partial t\right)^{5}$ is partitioned into the horizontal transport $\left(-\mathbf{V} \cdot \nabla_{h} q_{v}\right)$, the vertical transport $\left[-w\left(\partial q_{v} / \partial z\right)\right]$ and a residual component. The Residual component is calculated from $\left(\partial q_{v} / \partial t\right)+\left(\mathbf{V} \cdot \nabla_{h} q_{v}\right)+w\left(\partial q_{v} / \partial z\right)$, and in reality includes the contribution from subgrid mixing in the boundary layer, condensation/evaporation effects and computational errors (e.g., interpolation error).

The accumulated tendency of $q_{v}$ during the period 1300 2000 UTC is larger in the CTL run than that in the NOTER_LO, NOTER_L, NOTER_S, and NOTER_SO runs, which mainly comes from the differences in the vertical transport of $q_{v}$ (Fig. 9b). The lifting resulting from the MBLJ-driven ascent, coastal convergence, and orographic uplift contributes to the vertical transport of

\footnotetext{
${ }^{5} \partial q_{v} / \partial t$ is calculated by hourly centered time difference as $\left(\partial q_{v} / \partial t\right)_{t}=\left(q_{v_{t+\Delta t}}-q_{v_{t-\Delta t}}\right) / 2 \Delta t$, where $\Delta t=1 \mathrm{~h}$. The errors of calculation might depend on the temporal resolution of the difference.
}
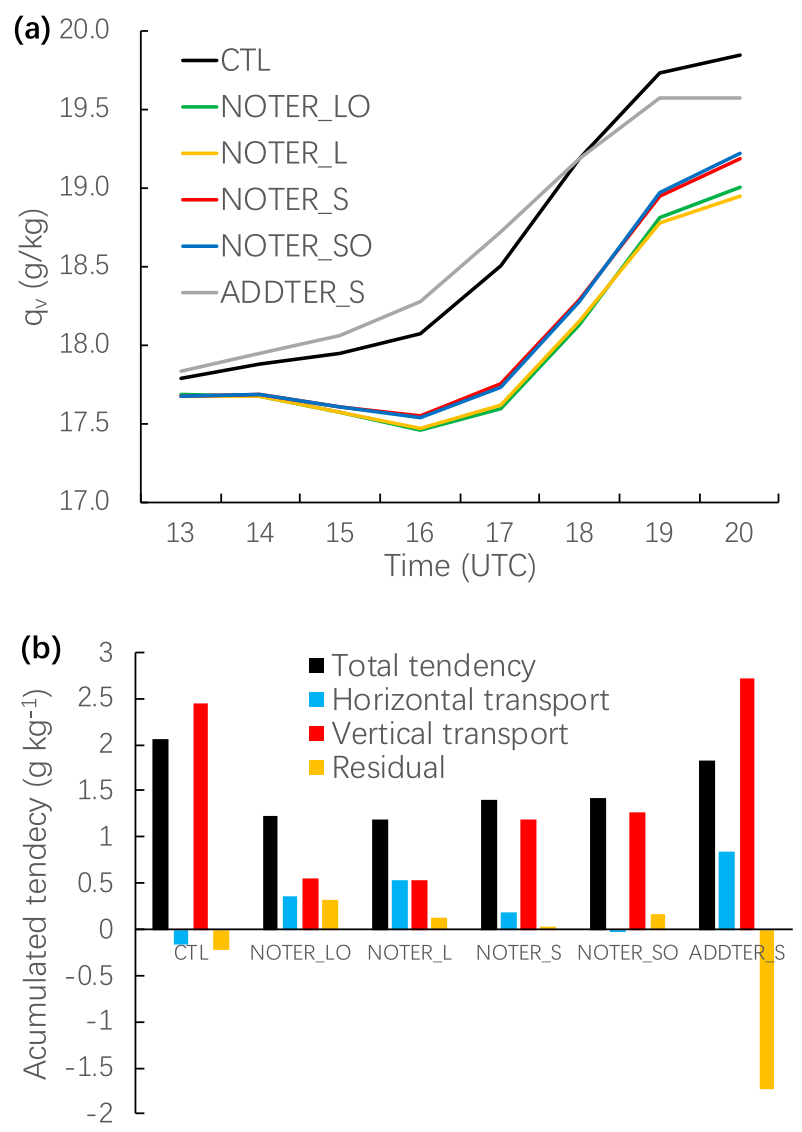

FIG. 9. (a) Time evolution of the water vapor mixing ratio $\left(q_{v}\right.$, $\left.\mathrm{g} \mathrm{kg}^{-1}\right)$ at $950 \mathrm{hPa}$ averaged over the black box in Fig. 8 during 1300-2300 UTC 21 Jun. (b) Accumulated tendency of $q_{v}\left(\mathrm{~g} \mathrm{~kg}^{-1}\right.$, black bars) at $950 \mathrm{hPa}$ during 1300-2300 UTC 21 Jun, and their contributions including horizontal transport (blue bars), vertical transport (red bars), and residual term (orange bars), in the CTL run and other sensitivity experiments.

$q_{v}$. Owing to the absence of either of the above lifting mechanisms in the sensitivity tests of terrain, low-level moistening is not as significant as that in the CTL run. Since moisture is centered in the concave region in the CTL run, the horizontal transport term $\left(-\mathbf{V} \cdot \nabla_{h} q_{v}\right)$ averaged in that region is relatively weak (Fig. $9 \mathrm{~b}$ ). In other experiments, the horizontal transport term fairly contributes to the local tendency of $q_{v}$ because of a large northsouth gradient of $q_{v}$ in the target region, particularly for the ADDTER_S run in which the moisture flux is blocked by the additional mountains (Fig. 9b). Furthermore, although both the vertical transport and the horizontal transport terms are larger in the ADDTER_S run than those in the CTL run, the local tendency is similar to that in the CTL run because of a negative residual term (Fig. 9b). The negative residual term results from the conversion of water vapor into cloud or rainwater due to the earlier occurrence of clouds and convection (Fig. 3). 
Since the moisture budget is performed only at a single level $(950 \mathrm{hPa})$, we further calculate the vertically integrated water vapor fluxes $\left(\mathrm{kg} \mathrm{s}^{-1} \mathrm{~m}^{-1}\right)$ at low levels to illustrate horizontal moisture transportation according to

$$
Q=\frac{1}{g} \int_{P_{0}}^{P_{1}} q V d p,
$$

where $g$ is the gravitational constant, $q$ is the water vapor mixing ratio, $V$ is the wind velocity perpendicular to a given boundary, and $P_{0}$ and $P_{1}$ are 1000 and $900 \mathrm{hPa}$, respectively. The plane integration of the vertically integrated water vapor fluxes $\left(\mathrm{kg} \mathrm{s}^{-1}\right)$ along the boundary from $x_{1}$ and $x_{2}$ is calculated as

$$
\overline{Q_{x_{1} x_{2}}}=\int_{x_{1}}^{x_{2}} Q d x .
$$

To obtain the net moisture fluxes in the concave region (black box in Fig. 8), we add up the plane integrations of the water vapor fluxes from the four boundaries as (Du and Chen 2019b)

$$
Q_{\text {net }}=\overline{Q_{\text {south_plane }}}+\overline{Q_{\text {north_plane }}}+\overline{Q_{\text {west_plane }}}+\overline{Q_{\text {east_plane }}} \text {. }
$$

Figure 10 displays the net moisture fluxes and related integrated moisture fluxes from the northern, southern, western and eastern boundaries in the different experiments. The net moisture fluxes in the CTL $(22.3 \times$ $\left.10^{5} \mathrm{~kg} \mathrm{~s}^{-1}\right)$ and ADDTER_S runs $\left(51.3 \times 10^{5} \mathrm{~kg} \mathrm{~s}^{-1}\right)$ are much larger than those in the other experiments because of the larger differences in the integrated moisture fluxes between the southern and northern boundaries (Fig. 10), which mainly results from the obstacle of the concave mountains. Larger net moisture fluxes in the target region in the ADDTER_S run favor earlier CI and UCG than those in the control run. Due to the absence of the large-scale terrain in the NOTER_L and NOTER_LO runs, the MBLJ can migrate more to the north without the obstacles of the coastline and terrain (Fig. 7), which induces almost zero net moisture flux in the actual concave region (Figs. 10b,c). The NOTER_S and NOTER_SO runs are characterized by slightly larger net moisture fluxes $\left(9.6 \times 10^{5}\right.$ and $6.6 \times 10^{5} \mathrm{~kg} \mathrm{~s}^{-1}$, respectively) than those in the NOTER_L and NOTER_LO runs (cf. Figs. 10b,c and 10d,e) because of the obstacle of the northern mountains (convergence on the south side of the mountains). The difference in the net moisture fluxes between the NOTER_S and NOTER_SO runs is attributed to coastal moisture convergence (cf. Figs. 10d and 10e). The larger moisture fluxes at the northern boundary lead to more moisture transport to the north in the
NOTER_SO run compared to that in the NOTER_S run (cf. Figs. 10d and 10e). Previous studies (e.g., Li et al. 2020) mainly stressed the orographic lifting of coastal terrain regardless of its thermodynamic role. Our analysis indicates that the coastal concave terrain is critical to the lowlevel moisture accumulation (positive net moisture fluxes) within the concave region by the terrain obstacle.

To further examine the role of concave terrain geometry, we conducted an additional experiment where the Nanyang Mountains are removed and only the linear Lianhua Mountains are retained. CI and UCG can still occur on the windward side of the Lianhua Mountains but convection can generate and develop more toward the northeast (not shown). Compared to the CTL run (Fig. 8a), more moisture is transported on the lee side of the original Nanyang Mountains without the blocking of the Nanyang Mountains (not shown). Therefore, concave terrain geometry of the Nanyang Mountains region can modulate the location of CI and UCG.

\section{Cold pool effects}

As shown in Fig. 1, convection is initiated at the vertex of concave terrain and then gradually develops into a larger MCS with southeastward movement. Previous studies (e.g., Ducrocq et al. 2008) suggest that new convection is triggered at the edge of the cold pool, which is primarily generated by the evaporative cooling of air within the downdraft region of deep convection. The spreading of the cold pool can be influenced by the terrain nearby and further affects the growth and movement of the convection. Next, we will examine the effect of the cold pools on the UCG processes in this event.

Cold pools are identified using thermal buoyancy, $B=g\left(\theta_{v}-\bar{\theta}_{v} / \bar{\theta}_{v}\right)$, where $g$ is the acceleration due to gravity $\left(\mathrm{m} \mathrm{s}^{-2}\right), \theta_{v}$ is the virtual potential temperature $(\mathrm{K})$, and $\bar{\theta}_{v}$ is the virtual potential temperature $(\mathrm{K})$ horizontally averaged over the black box of Fig. 2 a. Figures $11 \mathrm{a}-\mathrm{d}$ show the evolution of the cold pool by the thermal buoyancy at a $250-\mathrm{m}$ height during the period 2300-0200 UTC. Owing to the obstacle of the SW-NE-oriented Lianhua Mountains on the north, the leading edge of the cold pool propagates southeastward at a speed of $\sim 4.4 \mathrm{~m} \mathrm{~s}^{-1}$ (yellow dashed lines of Fig. 11d) and encounters nearly southerly and southwesterly low-level flows from the ocean. Since the background low-level wind $(1000-950 \mathrm{hPa})$ perpendicular to the leading edge of the cold pool averaged over the red box of Fig. 11c is approximately $5.1 \mathrm{~m} \mathrm{~s}^{-1}$, the propagation speed of the cold pool relative to the background low-level wind is approximately $9.5 \mathrm{~m} \mathrm{~s}^{-1}$. It is noted that the southern flank leading edge of the 
(a) CTL
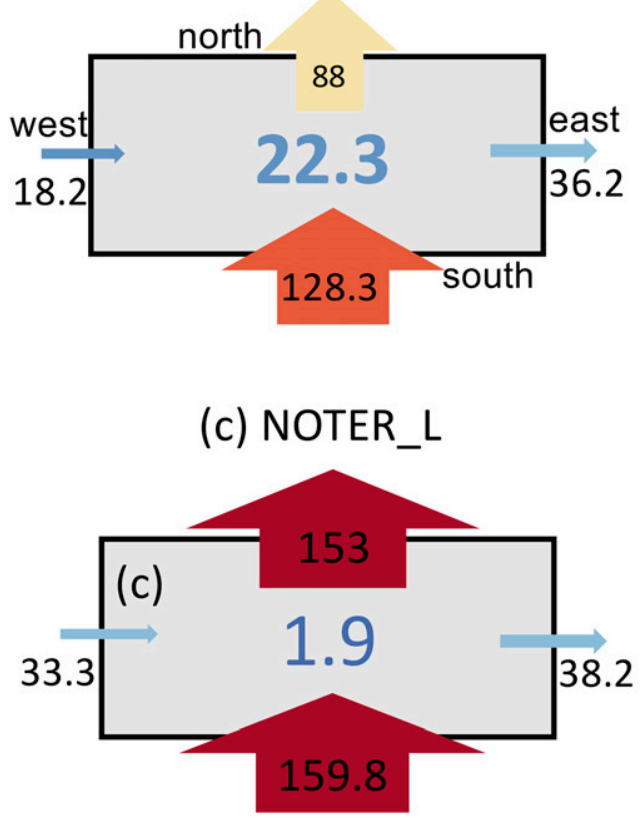

(e) NOTER_SO

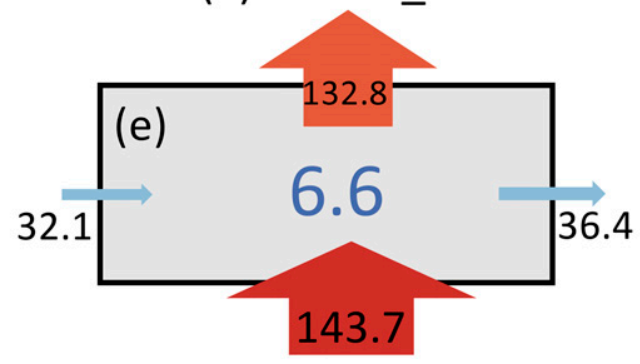

(b) NOTER_LO

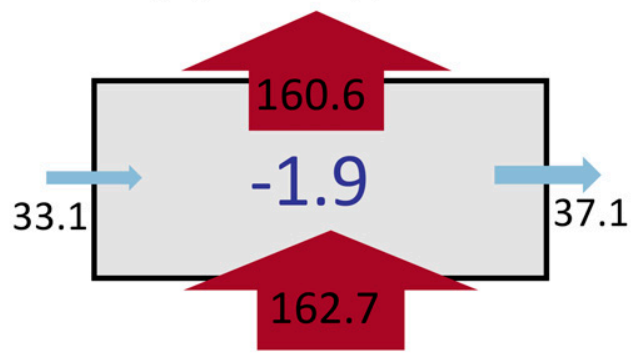

(d) NOTER_S

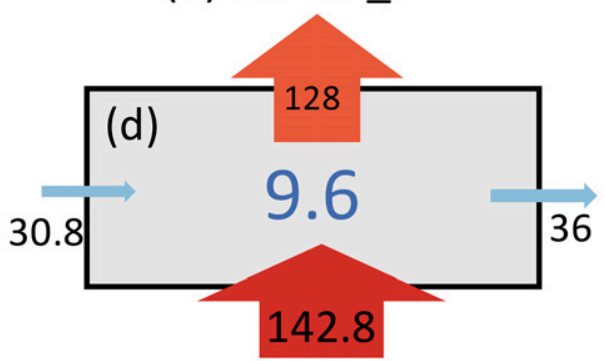

(f) ADDTER_S

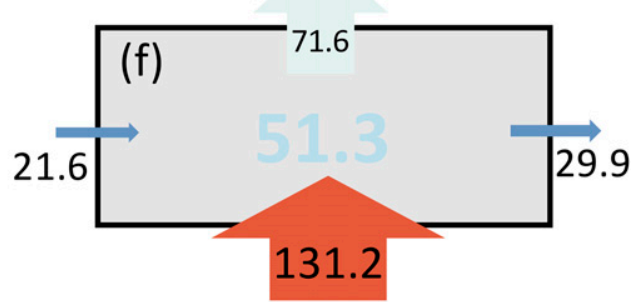

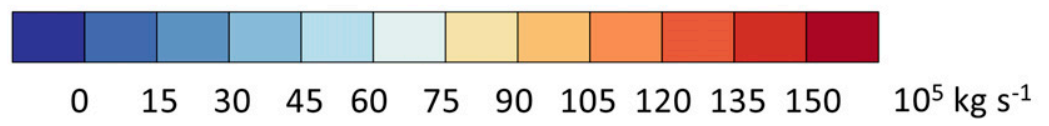

FIG. 10. Net moisture flux and integrated vapor transport (unit: $10^{5} \mathrm{~kg} \mathrm{~s}^{-1}$ ) from north, south, west, and east fluxes at 2000 UTC in the (a) CTL, (b) NOTER_LO, (c) NOTER_L, (d) NOTER_S, (e) NOTER_SO, and (f) ADDTER_S runs.

cold pool moves southward slightly once it reaches the coast between 0000 and 0200 UTC. The southerly maritime flows serve to stagnate the southward propagation of the cold pool because the southerly lowlevel background wind averaged over the blue box of Fig. 11c $\left(\sim 9.1 \mathrm{~m} \mathrm{~s}^{-1}\right)$ nearly equals the propagation speed of the cold pool itself $\left(\sim 9.5 \mathrm{~m} \mathrm{~s}^{-1}\right)$. These processes are also observed when an MCS interacts with an LLJ (Coniglio et al. 2011). Vertical cross sections of the thermal buoyancy and vertical motion along the black line in Fig. 11 clearly display that profound uplift (approximately $0.3-0.5 \mathrm{~m} \mathrm{~s}^{-1}$ within the layer of 1000 $900 \mathrm{hPa}$ ) at the leading edge of the cold pool expands southeastward (right side of Figs. 12a-d), which results in new convection initiation.

According to RKW theory (Rotunno et al. 1988; Weisman and Rotunno 2004), the deepest lifting at the leading edge of the cold pool occurs when the circulation associated with the cold pool is nearly balanced with that of the low-level shear. The RKW "optimal" state is envisioned when $C / \Delta u$ is close to 1 , where $C$ is the strength of the cold pool and $\Delta u$ is the vertical wind 

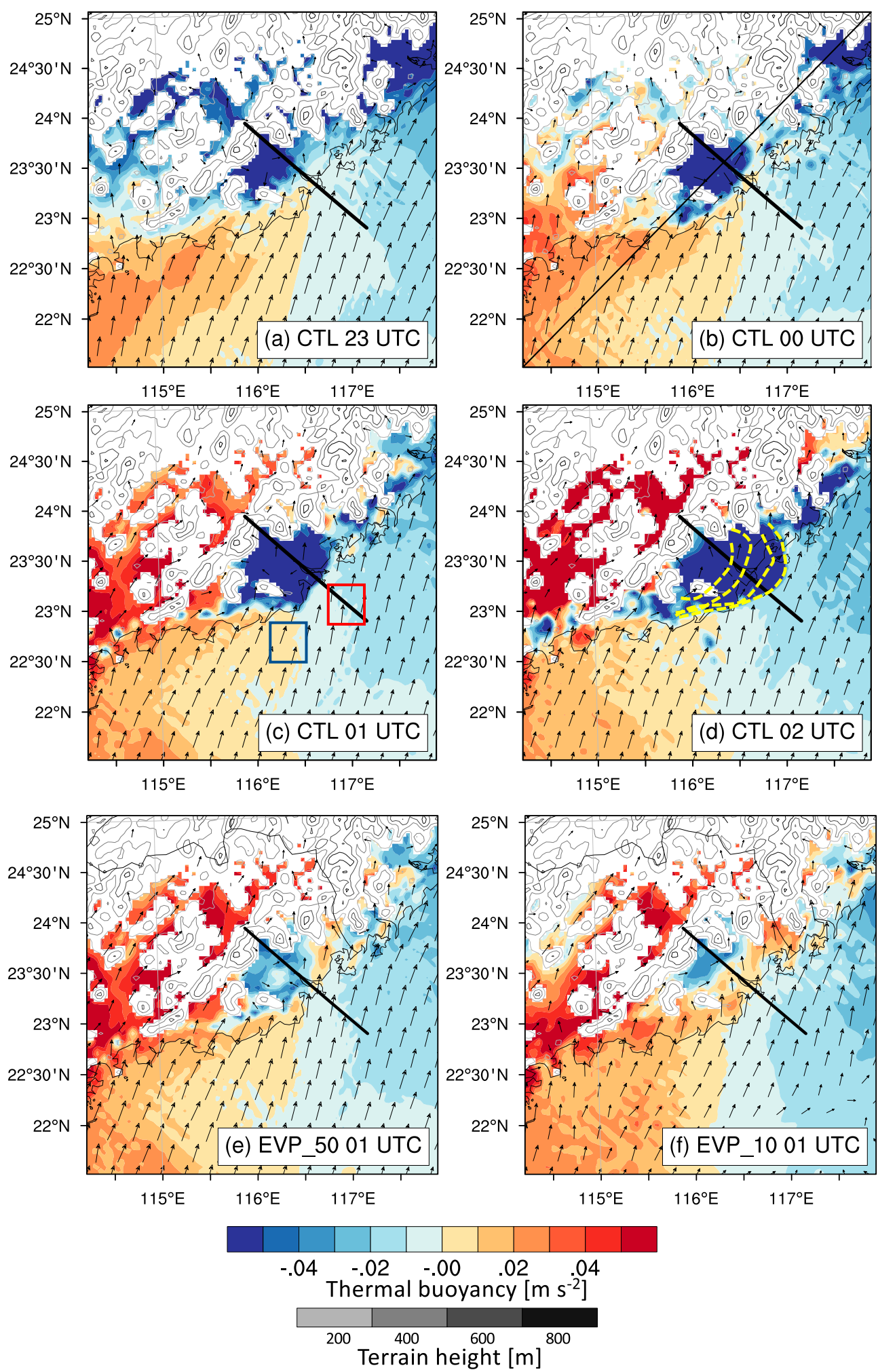

FIG. 11. Thermal buoyancy (shaded) with wind vectors at $250 \mathrm{~m}$ and terrain height (contours, intervals of $200 \mathrm{~m}$ ) from (a)-(d) 2300 UTC 21 Jun to 0200 UTC 22 Jun 2018 in the CTL run, and at 0100 UTC 21 Jun 2018 in the (e) EVP_50 and (f) EVP_10 runs. The black line is used in Fig. 12. The yellow dashed lines in (d) indicate the leading edge of the cold pool from 2300 UTC 21 Jun to 0200 UTC 22 Jun 2018. 

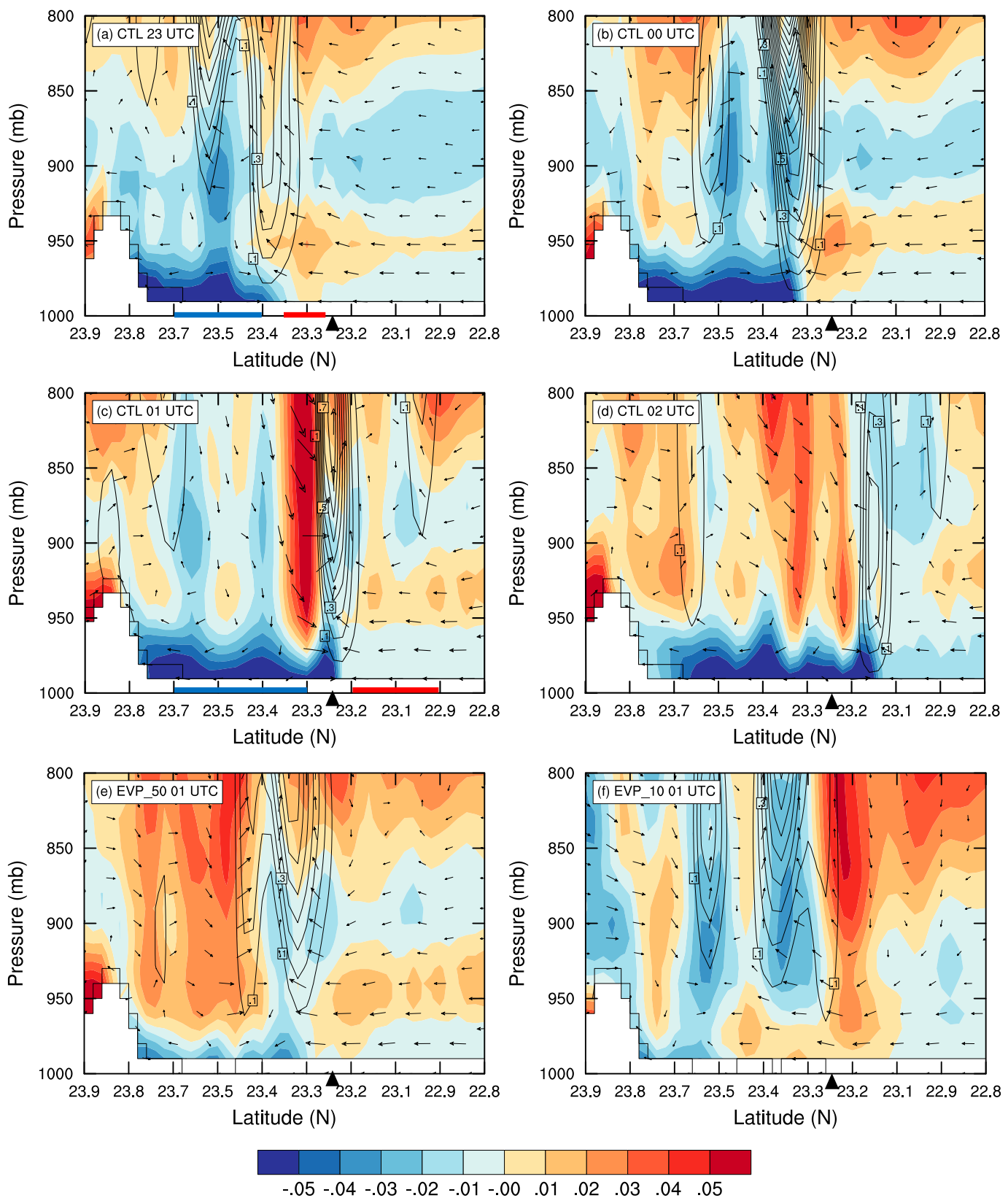

\section{Thermal buoyancy $\left[\mathrm{m} \mathrm{s}^{-2}\right]$}

FIG. 12. Vertical cross sections of buoyancy perturbation (shaded, $\mathrm{m} \mathrm{s}^{-2}$ ), vertical motion (contours $\geq 0.1 \mathrm{~m} \mathrm{~s}^{-1}$ with an interval of $0.1 \mathrm{~m} \mathrm{~s}^{-1}$ ) and flow vectors (black vectors, wind in the $y$ direction and 10 times the vertical velocity) from (a)-(d) 2300 UTC 21 Jun to 0200 UTC 22 Jun 2018 in the CTL run, and at 0100 UTC 22 Jun 2018 in the (e) EVP_50 and (f) EVP_10 runs. The black triangles indicate the location of the coastline. The blue and red lines in (a) and (c) are used to calculate the strength of the cold pool and vertical wind shear.

shear in the lowest $3 \mathrm{~km}$ AGL perpendicular to the leading edge of the cold pool. $C$ is estimated by

$$
C=\sqrt{2 \int_{0}^{H}-B d z}
$$

where $H$ is the height of the cold pool and $B$ is the thermal buoyancy. At 0100 UTC 22 June, the strength of the cold pool averaged along the blue line of Fig. 12c is approximately $5 \mathrm{~m} \mathrm{~s}^{-1}(H=400 \mathrm{~m}, \bar{B}=0.032)$, while $\Delta u$ averaged along the red line of Fig. $12 \mathrm{c}$ equals to $4.7 \mathrm{~m} \mathrm{~s}^{-1}$. Hence, a $C / \Delta u$ close to 1 favors deep lifting at 

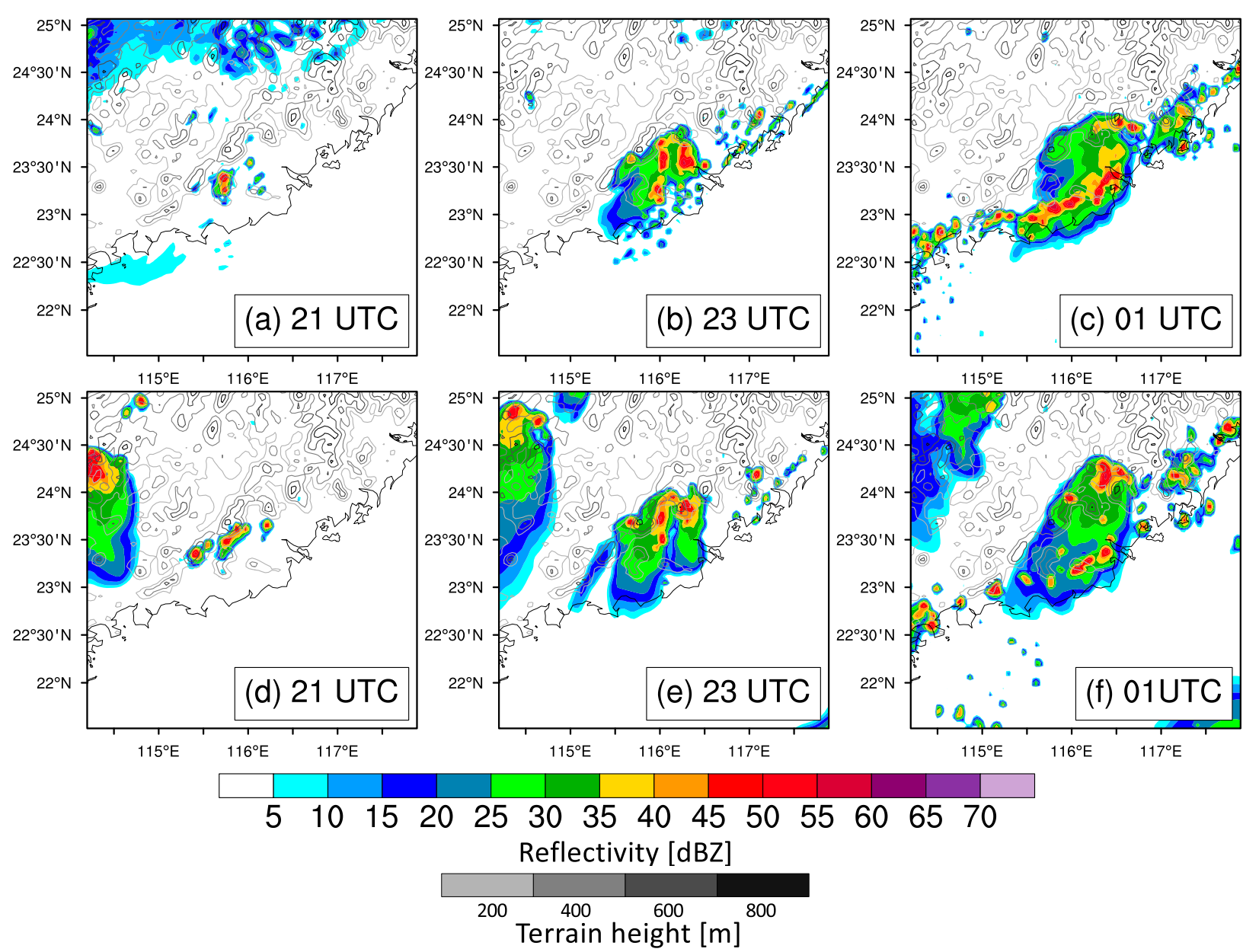

FIG. 13. Radar composite reflectivity (shaded) and terrain height (contours, intervals of $200 \mathrm{~m}$ ) in (a)-(c) EVP_50 and (d)-(f) EVP_10 runs from 2100 UTC 21 Jun to 0100 UTC 22 Jun 2018.

the leading edge of the cold pool. The shape of the cold pool edge has a nearly $90^{\circ}$ slope (Fig. 12c) in the optimal state, which is consistent with Bryan and Rotunno (2014). In contrast, a nonoptimal RKW sate occurs at 2300 UTC 21 June because $C / \Delta u$ is not close to 1 . Surface friction and terrain blocking reduce the lowlevel wind shear $\left(\sim 2.2 \mathrm{~m} \mathrm{~s}^{-1}\right.$ averaged over the red line of Fig. 12a), while the strength of the cold pool remains $\sim 5 \mathrm{~m} \mathrm{~s}^{-1}$. The slope of the leading edge is thus shallow (Fig. 12a). The RKW theory is generally applied to "strong squall lines" as one of mechanisms for maintaining longevity, while it may also partly explain the longevity of the intense coastal MCS along the southern China coast.

To verify the impact of the cold pool on the UCG process, we carried out sensitivity experiments where the latent cooling rate from the evaporation of rain is reduced to 50\% (EVP_50) and 10\% (EVP_10). In the two experiments, evaporation is still allowed, but the associated cooling is artificially reduced. The EVP_50 and EVP_10 runs are designed to explore the UCG processes with very little and moderate cold pool development. In the EVP_50 and EVP_10 runs, the CI process is similar to that in the CTL run, but the UCG process varies in intensity and location (Figs. 13 and 4). Compared to the CTL run, the development of the MCS in intensity becomes weaker in the two sensitivity experiments, particularly for the EVP_10 run $(\sim 1 / 4$ the intensity of the control run, red dashed line versus black solid line of Fig. 4). In the latter sensitivity experiments, the cold pools and the associated lifting at the leading edges of the cold pools are weakened correspondingly compared to that in the CTL run as their latent cooling rate from the evaporation of rain is reduced (cf. Figs. 11e,f and 11c; cf. Figs. 12e,f and 12c). The cold pool in the EVP_10 run is too weak to move (Figs. 11f and 12f), which results in the northeastward movement of the MCS under the effect of southwesterly background winds rather than the southeastward movement. New convective cells are still generated individually along the coast due to convergence induced by the coastline or coastal 
terrain, but they are not merged and organized (Fig. 13f) without the help of the cold pool in the EVP_10 run.

Consequently, cold pools indeed exert an important influence on the development of the SW-NE-oriented quasilinear MCS. The cold pool is blocked by the Lianhua Mountains and propagates southeastward, and then new convection is continually triggered at the southeastern edge of the cold pool, which helps to organize a SW-NEoriented quasi-linear MCS.

\section{Summary}

In the current study, we examine the effects of the terrain, coastline and cold pools on convection initiation (CI) and the subsequent upscale convective growth (UCG) processes in the case of heavy rainfall in South China (21-22 June 2018); this work is Part II of the study of Du et al. 2020 (Part I), which documented the impact of the marine boundary layer jet. A convection-permitting WRF-ARW simulation (CTL run) with a horizontal grid spacing of $4 \mathrm{~km}$ captures the location and timing of CI and UCG compared to those of the observations. The CI and UCG processes are demonstrated to be closely related to the coastal terrain. Convection is generated at the vertex of the concave terrain consisting of the SW-NE-oriented Lianhua Mountains and an NW-SE-oriented Nanyang Mountains. Subsequently, the convection is gradually organized into a larger mesoscale convective system (MCS) along with a southeastward propagation. The MCS contiguously grows along the coast and forms a SW-NE-oriented quasi-linear MCS remaining stationary in the coastal region. To clearly demonstrate the effects of the terrain, coastline and cold pools on CI and UCG, a schematic diagram is summarized in Fig. 14.

By carrying out a series of sensitivity experiments on multiscale terrain, we attempt to clarify the relative roles of large-scale terrain, local-scale concave terrain, and the coastline in CI and UCG. When the large-scale terrain of South China is removed and replaced by the ocean, CI and UCG disappear on the location of the actual coast due to the absence of coastal convergence, orographic uplift and MBLJ-driven ascent since the MBLJ can migrate farther to the north. By removing the large-scale terrain but retaining the coastline (not replaced by the ocean), CI and UCG still occur on the coast but are much weaker than those in the CTL run; they occur as a result of remaining weak coastal convergence by the variation in sea-land roughness. Therefore, the large-scale terrain and coastline of South China greatly influence the occurrence and intensity of convection as the synoptic background (e.g., MBLJ) correspondingly alters.

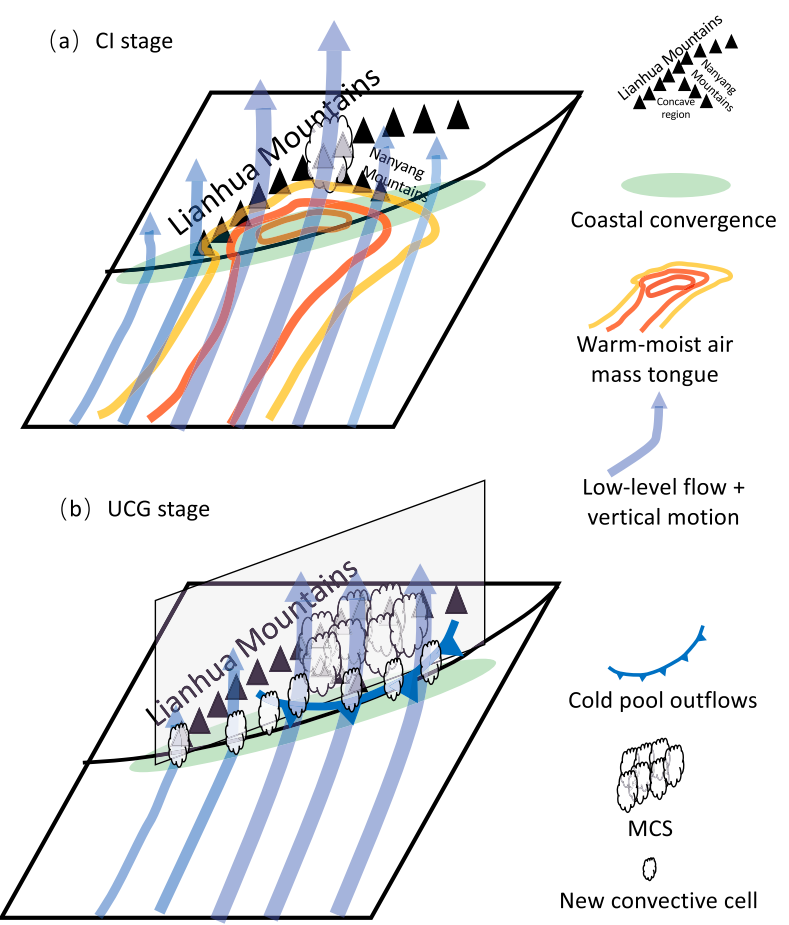

FIG. 14. Schematic diagram depicting convective initiation and growth near concave terrain under the effects of the coastal terrain, coastline, and cold pools.

By contrast, the small-scale terrain can strongly regulate the location and timing of CI and UCG. When the local concave terrain is removed, scattered CI and subsequent UCG occur near the coastal area instead of at the vertex of the location of the actual concave terrain owing to the absence of orographic lifting by the concave terrain. After the removed concave terrain is further replaced by the ocean, CI and UCG occur at the location of the actual coast as well as over the foothills of the northern mountains. Although there is no coastal convergence or orographic lifting at the location of the actual coast, the MBLJ-driven ascent accompanied by a moist tongue promotes CI and UCG at that location; over the foothills of the northern mountains, local convergence along the new coastline and topographic lifting are jointly conductive to CI and UCG. Furthermore, in the ADDTER_S run where the concave region is filled by additional mountains, convection is triggered earlier and maintained along the coast compared to that in the CTL run.

From a thermodynamic perspective, the coastal concave terrain plays the role of a moisture "catcher," which blocks and enhances moisture at low levels within the concave region; the moisture source is mainly from an upstream warm moist air mass tongue. In the absence of such a moisture "catcher" in the NOTER_S and NOTER_SO 
runs, water vapor spreads farther north to a broader inland region, and thereby low-level moistening near the coast is not as significant as that in the CTL run; this lack of moistening results in delayed CI and weaker UCG. The low-level moistening processes are quantified by the moisture budget and net vertically integrated moisture fluxes in the various sensitivity tests. The obstacles of the large-scale terrain in South China and the local coastal concave terrain facilitate vertically integrated net moisture accumulation at low levels within the concave region and promote low-level moistening by orographic lifting.

The cold pool outflows resulting from the evaporation of precipitation propagate southeastward rather than along the background southerlies due to the obstacle of the coastal SW-NE-oriented terrain, which vitally affects the growth and movement of the MCS. New convection is continuously generated at the leading edge of the cold pool interacting with southerly low-level flows. The RKW theory may contribute such evolution at certain times. The background flow stagnates the southward propagation of the cold pool when it reaches the coast, contributing to the longevity of the MCS by maintaining updraft development. In the EVP_50 and EVP_10 runs where the latent cooling rate due to the evaporation of rain is reduced, the simulated MCS (UCG processes) tends to be weaker and motionless along with weaker cool pools.

This study is the second part of a two-part series study on convection initiation and growth along the coast of South China. Part I mainly focuses on the role of synoptic-mesoscale forcing such as the MBLJ, whereas the present study (Part II) concentrates on more-detailed local meso- to small-scale forcings. Multiple factors including different-scale terrains, coastlines and cold pools and their relative roles, are systematically considered. Their combination in different ways plays a key role in convection initiation and growth. The knowledge gained from this study provides a guide for forecasting in mountainous coastal environments. The contributions from SST, tropospheric instability and cold pool shear to the development of the MSC were not discussed in the present study, which will be explored in the future. Furthermore, we will climatologically investigate the large-scale or local terrain effects on rainfall distribution. The details on the evolution of the cold pool and relevant boundary layer features will be explored using the PBL tower observations.

Acknowledgments. This study was supported by the National Key Research and Development Program of China (Grant 2018YFC1507402), the National Natural Science Foundation of China (Grants 41875055, 41861164027, and 41775094), Guangzhou Science and Technology Plan Projects (202002030346), the Fundamental
Research Funds for the Central Universities (19lgzd08), and the Young Elite Scientists Sponsorship Program by CAST (2018QNRC001). The authors are grateful to Dr. Richard Rotunno from NCAR for his help in improving the manuscript.

\section{REFERENCES}

Bai, L., G. Chen, and L. Huang, 2020a: Image processing of radar mosaics for the climatology of convection initiation in South China. J. Appl. Meteor. Climatol., 59, 65-81, https://doi.org/ 10.1175/JAMC-D-19-0081.1.

,,-- and $-2020 \mathrm{~b}$ : Convection initiation in monsoon coastal areas (South China). Geophys. Res. Lett., 47, e2020GL087035, https://doi.org/10.1029/2020GL087035.

Bergeron, T., 1949: The problem of artificial control of rainfall on the globe II. The coastal orographic maxima of precipitation in autumn and winter. Tellus, 1, 15-32, https://doi.org/10.1111/ j.2153-3490.1949.tb01264.x.

Bryan, G. H., and R. Rotunno, 2014: The optimal state for gravity currents in shear. J. Atmos. Sci., 71, 448-468, https://doi.org/ 10.1175/JAS-D-13-0156.1.

Buzzi, A., and L. Foschini, 2000: Mesoscale meteorological features associated with heavy precipitation in the southern Alpine region. Meteor. Atmos. Phys., 72, 131-146, https:// doi.org/10.1007/s007030050011.

— of the 1994 Piedmont flood: Role of orography and moist processes. Mon. Wea. Rev., 126, 2369-2383, https://doi.org/ 10.1175/1520-0493(1998)126<2369:NSOTPF $>2.0$.CO;2.

Chen, C.-S., W.-S. Chen, and Z. Deng, 1991: A study of a mountain generated precipitation system in northern Taiwan during TAMEX IOP 8. Mon. Wea. Rev., 119, 2574-2607, https://doi.org/ 10.1175/1520-0493(1991)119<2574:ASOAMG > 2.0.CO;2.

_- C.-Y. Lin, Y.-J. Chuang, and H.-C. Yeh, 2002: A study of afternoon heavy rainfall in Taiwan during the mei-yu season. Atmos. Res., 65, 129-149, https://doi.org/10.1016/ S0169-8095(02)00061-3.

Chen, G., R. Lan, W. Zeng, H. Pan, and W. Li, 2018: Diurnal variations of rainfall in surface and satellite observations at the monsoon coast (South China). J. Climate, 31, 1703-1724, https://doi.org/10.1175/JCLI-D-17-0373.1.

Chen, G. T. J., and C. C. Yu, 1988: Study of low-level jet and extremely heavy rainfall over northern Taiwan in the mei-yu season. Mon. Wea. Rev., 116, 884-891, https://doi.org/10.1175/ 1520-0493(1988)116<0884:SOLLJA > 2.0.CO;2.

Chen, X., K. Zhao, and M. Xue, 2017: Influence of monsoonal wind speed and moisture content on intensity and diurnal variations of the mei-yu season coastal rainfall over south China. J. Atmos. Sci., 74, 2835-2856, https://doi.org/10.1175/JAS-D-17-0081.1.

Chu, C.-M., and Y.-L. Lin, 2000: Effects of orography on the generation and propagation of mesoscale convective systems in a two-dimensional conditionally unstable flow. J. Atmos. Sci., 57, 3817-3837, https://doi.org/10.1175/1520-0469(2001) 057<3817:EOOOTG $>2.0 . \mathrm{CO} ; 2$.

Coniglio, M. C., S. F. Corfidi, and J. S. Kain, 2011: Environment and early evolution of the 8 May 2009 derecho-producing convective system. Mon. Wea. Rev., 139, 1083-1102, https:// doi.org/10.1175/2010MWR3413.1.

Davis, C. A., and W.-C. Lee, 2012: Mesoscale analysis of heavy rainfall episodes from SoWMEX/TiMREX. J. Atmos. Sci., 69, 521-537, https://doi.org/10.1175/JAS-D-11-0120.1. 
Du, Y., and G. X. Chen, 2019a: Heavy rainfalls associated with double low-level jets over southern China. Part II: Convection initiation. Mon. Wea. Rev., 147, 543-565, https://doi.org/ 10.1175/MWR-D-18-0102.1.

— pact on rainfall over southern China during early-summer rainy season. J. Climate, 32, 8813-8833, https://doi.org/10.1175/ JCLI-D-19-0306.1.

,-- , B. Han, C. Mai, L. Bai, and M. Li, 2020: Convection initiation and growth at the coast of South China. Part I: Effect of the marine boundary layer jet. Mon. Wea. Rev., 148, 3847-3869, https://doi.org/10.1175/MWR-D-20-0089.1.

Ducrocq, V., O. Nuissier, D. Ricard, C. Lebeaupin, and T. Thouvenin, 2008: A numerical study of three catastrophic precipitating events over southern France. II: Mesoscale triggering and stationarity factors. Quart. J. Roy. Meteor. Soc., 134, 131-145, https://doi.org/10.1002/QJ.199.

Fu, P., K. Zhu, K. Zhao, B. Zhou, and M. Xue, 2019: Role of the nocturnal low-level jet in the formation of the morning precipitation peak over the Dabie Mountains. Adv. Atmos. Sci., 36, 15-28, https://doi.org/10.1007/s00376-018-8095-5.

Fulton, R. A., J. P. Breidenbach, D.-J. Seo, D. A. Miller, and T. O'Bannon, 1998: The WSR-88D Rainfall Algorithm. Wea. Forecasting, 13, 377-395, https://doi.org/10.1175/15200434(1998)013<0377:TWRA > 2.0.CO;2.

Lebeaupin, C., V. Ducrocq, and H. Giordani, 2006: Sensitivity of torrential rain events to the sea surface temperature based on high-resolution numerical forecasts. J. Geophys. Res., 111, D12110, https://doi.org/10.1029/2005JD006541.

Lee, J. T., D. I. Lee, C.-H. You, H. Uyeda, Y.-C. Liou, and I.-S. Han, 2014: Dual-Doppler radar analysis of a near-shore lineshaped convective system on 27 July 2011, Korea: A case study. Tellus, 66A, 23453, https://doi.org/10.3402/tellusa.v66.23453.

,$- \ldots$, S. Shimizu, and C. H. You, 2019: Analysis of determinants for an enhanced and long-lasting coastal convective system by means of a case study (26 July 2011). Adv. Atmos. Sci., 36, 1327-1339, https://doi.org/10.1007/s00376-019-9025-x.

Li, H., Q. Wan, D. Peng, X. Liu, and H. Xiao, 2020: Multiscale analysis of a record-breaking heavy rainfall event in Guangdong, China. Atmos. Res., 232, 104703, https://doi.org/ 10.1016/j.atmosres.2019.104703.

Li, J., Y.-L. Chen, and W.-C. Lee, 1997: Analysis of a heavy rainfall event during TAMEX. Mon. Wea. Rev., 125, 1060-1082, https:// doi.org/10.1175/1520-0493(1997)125<1060:AOAHRE>2.0.CO;2.

Lin, C.-Y., F. Chen, J. C. Huang, Y. A. Liou, W. C. Chen, W. N. Chen, and S.-C. Liu, 2008a: Urban heat island effect and its impact on boundary layer development and land-sea circulation over northern Taiwan. Atmos. Environ., 42, 5635-5649, https://doi.org/10.1016/j.atmosenv.2008.03.015.

- W.-C. Chen, S. C. Liu, Y. A. Liou, G. R. Liu, and T. H. Lin, 2008b: Numerical study of the impact of urbanization on the precipitation over Taiwan. Atmos. Environ., 42, 2934-2947, https://doi.org/10.1016/j.atmosenv.2007.12.054.

— - _ P.-L. Chang, and Y.-F. Sheng, 2011: Impact of urban heat island effect on the precipitation over complex geographic environment in northern Taiwan. J. Appl. Meteor. Climatol., 50, 339-353, https://doi.org/10.1175/2010JAMC2504.1.

Lin, Y.-L., S. Chiao, T.-A. Wang, M. L. Kaplan, and R. P. Weglarz, 2001: Some common ingredients for heavy orographic rainfall. Wea. Forecasting, 16, 633-660, https://doi.org/10.1175/15200434(2001)016<0633:SCIFHO >2.0.CO;2.

Liu, X., Y. Luo, Z. Guan, and D.-L. Zhang, 2018: An extreme rainfall event in coastal South China during SCMREX-2014: Formation and roles of rainband and echo trainings. J. Geophys. Res. Atmos., 123, 9256-9278, https://doi.org/10.1029/2018JD028418.

Luo, Y., and Coauthors, 2017: The Southern China Monsoon Rainfall Experiment (SCMREX). Bull. Amer. Meteor. Soc., 98, 999-1013, https://doi.org/10.1175/BAMS-D-15-00235.1.

_ , and Coauthors, 2020: Science and prediction of heavy rainfall over China: Research progress since the reform and openingup of new China. J. Meteor. Res., 34, 427-459, https://doi.org/ 10.1007/s13351-020-0006-x.

Maddox, R. A., 1983: Large-scale meteorological conditions associated with midlatitude, mesoscale convective complexes. Mon. Wea. Rev., 111, 1475-1493, https://doi.org/10.1175/15200493(1983)111<1475:LSMCAW>2.0.CO;2.

_ L. R. Hoxit, C. F. Chappell, and F. Caracena, 1978: Comparison of meteorological aspects of the big Thompson and rapid city flash floods. Mon. Wea. Rev., 106, 375-389, https://doi.org/ 10.1175/1520-0493(1978)106<0375:COMAOT >2.0.CO;2.

Miao, J.-E., and M.-J. Yang, 2020: A modeling study of the severe afternoon thunderstorm event at Taipei on 14 June 2015: The roles of sea breeze, microphysics, and terrain. J. Meteor. Soc. Japan, 98, 129-152, https://doi.org/10.2151/ jmsj.2020-008.

Miglietta, M. M., and A. Buzzi, 2001: A numerical study of moist stratified flows over isolated topography. Tellus, 53, 481-499, https://doi.org/10.3402/tellusa.v53i4.12222.

— regimes over isolated topography. Quart. J. Roy. Meteor. Soc., 130, 1749-1770, https://doi.org/10.1256/qj.02.225.

_ , and R. Rotunno, 2009: Numerical simulations of conditionally unstable flows over a ridge. J. Atmos. Sci., 66, 1865-1885, https://doi.org/10.1175/2009JAS2902.1.

— over a mountain ridge. J. Atmos. Sci., 67, 2391-2401, https:// doi.org/10.1175/2010JAS3378.1.

, and - 2012: Application of theory to observed cases of orographically forced convective rainfall. Mon. Wea. Rev., 140, 3039-3053, https://doi.org/10.1175/MWR-D-11-00253.1. , and 2014: Numerical simulations of sheared conditionally unstable flows over a mountain ridge. J. Atmos. Sci., 71, 1747-1762, https://doi.org/10.1175/JAS-D-13-0297.1.

Mulholland, J. P., S. W. Nesbitt, and R. J. Trapp, 2019: A case study of terrain influences on upscale convective growth of a supercell. Mon. Wea. Rev., 147, 4305-4324, https://doi.org/ 10.1175/MWR-D-19-0099.1.

Neiman, P. J., F. M. Ralph, A. B. White, D. E. Kingsmill, and P. O. G. Persson, 2002: The statistical relationship between upslope flow and rainfall in California's coastal mountains: Observations during CALJET. Mon. Wea. Rev., 130, 1468-1492, https://doi.org/ 10.1175/1520-0493(2002)130<1468:TSRBUF > 2.0.CO;2.

Nuissier, O., V. Ducrocq, D. Ricard, C. Lebeaupin, and S. Anquetin, 2008: A numerical study of three catastrophic precipitating events over Southern France. I: Numerical framework and synoptic ingredients. Quart. J. Roy. Meteor. Soc., 134, 111-130, https://doi.org/10.1002/qj.200.

Phadtare, J., 2018: Role of Eastern Ghats orography and cold pool in an extreme rainfall event over Chennai on 1 December 2015. Mon. Wea. Rev., 146, 943-965, https://doi.org/10.1175/ MWR-D-16-0473.1.

Romero, R., C. A. Doswell III, and C. Ramis, 2000: Mesoscale numerical study of two cases of long-lived quasi-stationary convective systems over eastern Spain. Mon. Wea. Rev., 128, 3731-3751, https://doi.org/10.1175/1520-0493(2001)129<3731: MNSOTC $>2.0 . \mathrm{CO} ; 2$. 
Rotunno, R., and R. Ferretti, 2001: Mechanisms of intense Alpine rainfall. J. Atmos. Sci., 58, 1732-1749, https://doi.org/10.1175/ 1520-0469(2001)058<1732:MOIAR > 2.0.CO;2.

—, and R. A. Houze, 2007: Lessons on orographic precipitation from the Mesoscale Alpine Programme. Quart. J. Roy. Meteor. Soc., 133, 811-830, https://doi.org/10.1002/qj.67.

— J. B. Klemp, and M. L. Weisman, 1988: A theory for strong, long-lived squall lines. J. Atmos. Sci., 45, 463-485, https://doi.org/ 10.1175/1520-0469(1988)045<0463:ATFSLL>2.0.CO;2.

Skamarock, W. C., and Coauthors, 2008: A description of the Advanced Research WRF version 3. NCAR Tech. Note NCAR/ TN-475+STR, 113 pp., https://doi.org/10.5065/D68S4MVH.

Smith, R. B., 1979: The influence of mountains on the atmosphere. Advances in Geophysics, Vol. 21, Academic Press, 87-230.

__, 2019: 100 Years of progress on mountain meteorology research. A Century of Progress in Atmospheric and Related Sciences: Celebrating the American Meteorological Society Centennial, Meteor. Monogr., No. 59, Amer. Meteor. Soc., https://doi.org/10.1175/AMSMONOGRAPHS-D-18-0022.1.

_ and Y.-L. Lin, 1982: The addition of heat to a stratified airstream with application to the dynamics of orographic rain. Quart. J. Roy. Meteor. Soc., 108, 353-378, https://doi.org/ 10.1002/qj.49710845605.

Soderholm, B., B. Ronalds, and D. J. Kirshbaum, 2014: The evolution of convective storms initiated by an isolated mountain ridge. Mon. Wea. Rev., 142,1430-1451, https://doi.org/10.1175/ MWR-D-13-00280.1.

Tu, C., Y. Chen, P. Lin, and Y. Du, 2019: Characteristics of the marine boundary layer jet over the South China Sea during the early summer rainy season of Taiwan. Mon. Wea. Rev., 147, 457-475, https://doi.org/10.1175/MWR-D18-0230.1.

Wang, H., Y. Luo, and B. Jou, 2014: Initiation, maintenance, and properties of convection in an extreme rainfall event during SCMREX: Observational analysis. J. Geophys. Res. Atmos., 119, 13 206-13 232, https://doi.org/10.1002/2014JD022339.
Wang, J.-J., R. M. Rauber, H. T. Ochs III, and R. E. Carbone, 2000: The effects of the island of Hawaii on offshore rainband evolution. Mon. Wea. Rev., 128, 1052-1069, https://doi.org/ 10.1175/1520-0493(2000)128<1052:TEOTIO > 2.0.CO;2.

Weckwerth, T. M., and D. B. Parsons, 2006: A review of convection initiation and motivation for IHOP_2002. Mon. Wea. Rev., 134, 5-22, https://doi.org/10.1175/MWR3067.1.

Weisman, M. L., and R. Rotunno, 2004: "A theory for strong long-lived squall lines" revisited. J. Atmos. Sci., 61, 361-382, https://doi.org/10.1175/1520-0469(2004)061<0361:ATFSLS> 2.0.CO;2.

Wu, N., X. Zhuang, J. Min, and Z. Meng, 2020: Practical and intrinsic predictability of a warm-sector extreme torrential rainfall event in the South China monsoon region. J. Geophys. Res. Atmos. 125, e2019JD031313, https://doi.org/10.1029/2019JD031313.

Wulfmeyer, V., and Coauthors, 2011: The Convective and Orographically-induced Precipitation Study (COPS): The scientific strategy, the field phase, and research highlights. Quart. J. Roy. Meteor. Soc., 137, 3-30, https://doi.org/10.1002/qj.752.

Xu, W., E. J. Zipser, Y.-L. Chen, C. Liu, Y.-C. Liou, W.-C. Lee, and B. Jong-Dao Jou, 2012: An orography-associated extreme rainfall event during TiMREX: Initiation, storm evolution, and maintenance. Mon. Wea. Rev., 140, 2555-2574, https:// doi.org/10.1175/MWR-D-11-00208.1.

Yu, C.-K., and Y.-H. Hsieh, 2009: Formation of the convective lines off the mountainous coast of southeastern Taiwan: A case study of 3 January 2004. Mon. Wea. Rev., 137, 3072-3091, https://doi.org/10.1175/2009MWR2867.1.

— D. P. Jorgensen, and F. Roux, 2007: Multiple precipitation mechanisms over mountains observed by airborne Doppler radar during MAP IOP5. Mon. Wea. Rev., 135, 955-984, https://doi.org/10.1175/MWR3318.1.

Zhao, Y., 2012: Numerical investigation of a localized extremely heavy rainfall event in complex topographic area during midsummer. Atmos. Res., 113, 22-39, https://doi.org/10.1016/ j.atmosres.2012.04.018. 